\title{
Analysis of the positive ionospheric response to a moderate geomagnetic storm using a global numerical model
}

\author{
A. A. Namgaladze ${ }^{1,2}$, M. Förster ${ }^{3}$, R. Y. Yurik ${ }^{2}$ \\ ${ }^{1}$ Murmansk State Technical University, Murmansk, Russia \\ e-mail: Namgaladze@mstu.edu.ru \\ ${ }^{2}$ Polar Geophysical Institute, Russian Academy of Sciences, Murmansk, Russia \\ ${ }^{3}$ Max-Planck-Institut für extraterrestrische Physik, Garching near Munich, Germany \\ e-mail: mfo@mpe.mpg.de
}

Received: 24 September 1999 / Revised: 15 December 1999 / Accepted: 13 January 2000

\begin{abstract}
Current theories of $F$-layer storms are discussed using numerical simulations with the Upper Atmosphere Model, a global self-consistent, time dependent numerical model of the thermosphere-ionosphere-plasmasphere-magnetosphere system including electrodynamical coupling effects. A case study of a moderate geomagnetic storm at low solar activity during the northern winter solstice exemplifies the complex storm phenomena. The study focuses on positive ionospheric storm effects in relation to thermospheric disturbances in general and thermospheric composition changes in particular. It investigates the dynamical effects of both neutral meridional winds and electric fields caused by the disturbance dynamo effect. The penetration of short-time electric fields of magnetospheric origin during storm intensification phases is shown for the first time in this model study. Comparisons of the calculated thermospheric composition changes with satellite observations of AE-C and ESRO-4 during storm time show a good agreement. The empirical MSISE90 model, however, is less consistent with the simulations. It does not show the equatorward propagation of the disturbances and predicts that they have a gentler latitudinal gradient. Both theoretical and experimental data reveal that although the ratio of $[\mathrm{O}] /\left[\mathrm{N}_{2}\right]$ at high latitudes decreases significantly during the magnetic storm compared with the quiet time level, at mid to low latitudes it does not increase (at fixed altitudes) above the quiet reference level. Meanwhile, the ionospheric storm is positive there. We conclude that the positive phase of the ionospheric storm is mainly due to uplifting of ionospheric $F_{2}$-region plasma at mid latitudes and its equatorward movement at low latitudes along geomagnetic field lines caused by large-scale neutral wind circulation and the passage of travelling atmospheric disturbances (TADs). The calculated zonal electric field disturbances also help to create the positive ionospheric disturbances both at middle and low latitudes. Minor contributions arise from the
\end{abstract}

Correspondence to: M. Förster general density enhancement of all constituents during geomagnetic storms, which favours ion production processes above ion losses at fixed height under daylight conditions.

Key words: Atmospheric composition and structure (thermosphere-composition and chemistry) Ionosphere (ionosphere-atmosphere interactions; modeling and forecasting)

\section{Introduction}

Seventy years after their discovery, despite several decades of intensive study, ionospheric storms remain a most fascinating and challenging topic for the ionosphere-thermosphere community. In recent years, global-scale numerical modelling has provided a new impetus to the study of magnetospheric storms and their concomitant thermospheric and ionospheric disturbances. Simulation studies enable the construction of "experimental" storm scenarios on a global scale, and allow the integration of diverse data sets to investigate the complex physical phenomena.

Global-scale modelling of the thermospheric behaviour began in the early 1980s with the development of thermospheric general circulation models (TGCMs), such as those by the University College London (UCL) (Fuller-Rowell and Rees, 1980, 1983) and the National Center for Atmospheric Research (NCAR)(Dickinson et al., 1981, 1984). The next step was to include ionospheric layers as, e.g., in the UCL - Sheffield University thermosphere/ionosphere studies (FullerRowell et al., 1987, 1988) or in the more recent version of the NCAR thermosphere/ionosphere general circulation model (TIGCM) (Roble et al., 1988). Further refinement was achieved by the additional incorporation of the plasmasphere, as by Namgaladze et al. (1988). Because large-scale electrodynamics play an important 
role in the neutral and plasma dynamics of the upper atmosphere and in its interplay with the plasmasphere and magnetosphere, further development of the models led to the construction of thermosphere/ionosphere electrodynamics general circulation models (TIEGCMs) as, e.g., by Namgaladze et al. (1991), Richmond et al. (1992) and more recently by Peymirat et al. (1998).

The first coupled numerical modelling studies of the geomagnetically induced thermospheric composition changes and their ionospheric effects were performed by Fuller-Rowell et al. $(1987,1990,1991)$ and Rishbeth et al. (1987). More recent work of Fuller-Rowell et al. (1994) and Burns et al. (1995a, b) provoked the present investigations. Their results led them to conclude that there is a significant enhancement of the $[\mathrm{O}] /\left[\mathrm{N}_{2}\right]$ ratio in the evening sector of the mid-latitude winter hemisphere, providing an essential contribution to the positive storm effect there.

Ionospheric scientists have come to a general understanding of the causes of negative ionospheric storms (electron density depletions at $F$-layer heights) at high to mid latitudes. They are due to the decreased $[\mathrm{O}] /\left[\mathrm{N}_{2}\right]$ ratio within the perturbation zone which develops during magnetic storms near the auroral ovals. The situation with positive storms (electron density enhancements) is quite different.

Our study focuses on positive ionospheric storm effects. It investigates the relative role of thermospheric composition effects and dynamical forces of the thermospheric winds and electric fields. Preliminary results of our study have been presented in the paper of Förster et al. (1999); in this study we show more detailed numerical results. They comprise global maps of [O], $\left[\mathrm{N}_{2}\right],\left([\mathrm{O}] /\left[\mathrm{N}_{2}\right]\right), N_{e}$ and wind disturbances at $300 \mathrm{~km}$ height as well as $h_{m} F_{2}$ and $N_{m} F_{2}$ for different UT. Further, we present the storm time evolution of the disturbances of neutral mass density, temperature, $([\mathrm{O}] /$ $\left.\left[\mathrm{N}_{2}\right]\right), N_{m} F_{2}$, wind and zonal electric field disturbances at the 1200 MLT meridian.

Section 2 gives a short overview of the current status of this field of research while Sect. 3 presents the numerical modelling task to be tackled in this study. The simulation results are shown in Sect. 4, in Sect. 5 the results are discussed and compared with observations, in Sect. 6 a summary of the work is given.

\section{Thermosphere disturbances and $\boldsymbol{F}$-layer storm effects}

Negative ionospheric storms (electron density depletions in the $F$-layer) are explained almost without exception as a consequence of the decreased concentration ratio $[\mathrm{O}] /$ $\left[\mathrm{N}_{2}\right]$ during magnetic storms resulting in an ion loss rate enhancement (e.g. Prölss, 1980, 1995, and references therein). The situation with positive ionospheric storms is more complicated. Overviews of various conflicting explanations are given in various review articles (e.g. Matuura, 1972; Danilov and Morozova, 1985; Prölss, 1995, 1997). Many hypotheses have been tried and most rejected (see, e.g. the tabular overview by Prölss, 1995). Currently, there exist a few competing theories to explain positive disturbances at middle and low latitudes.

The most favoured is the old idea that changes in the pattern of the meridional winds cause a vertical motion of the ionized layer along geomagnetic field lines. An equatorward-directed neutral wind drives ionospheric plasma along the geomagnetic field lines upward to where the ion loss rates are smaller (Jones and Rishbeth, 1971). Disturbance dynamo or other electric fields could result in a similar effect, raising the $F_{2}$-layer height. The changed neutral wind circulation is largely due to increased high-latitude energy input during geomagnetic storms (mainly resulting from Joule heating) inducing the generation of large-scale gravity waves, the travelling atmospheric disturbances (Prölss, 1980). The latter give rise to short-duration, transient positive ionospheric perturbations while the large-scale circulation change associated with upwelling at high latitudes and downwelling at middle and low latitudes leads to a redistribution of the thermospheric constituents. Around the auroral upwelling zones so-called disturbance regions with a decreased $[\mathrm{O}] /\left[\mathrm{N}_{2}\right]$ ratio are created. These are moved forward and backward in the meridional direction by changing neutral winds during the course of the day while corotating simultaneously with the Earth (Prölss, 1981). The equatorward latitudinal extent of the disturbance regions is limited by quite sharply defined boundaries (Skoblin and Förster, 1995; Zuzic et al., 1997), inside of which negative ionospheric perturbations can be expected. These mechanisms have been accepted as the principal causes of ionospheric storms for many years.

Neutral gas composition changes at mid to low latitudes have been considered as possible candidates for positive ionospheric disturbances mainly as the result of global-scale modelling efforts in the last decade. The increase of the concentration ratio $[\mathrm{O}] /\left[\mathrm{N}_{2}\right]$ was proposed as the main cause for a positive storm phase in these latitudes.

In addition to the hypothetical composition changes at mid to low latitudes there is a general increase of the density of all thermospheric constituents (at fixed heights) mainly due to the globally enhanced thermospheric temperature during geomagnetic storms. Observations reveal that the density increase is proportional for all constituents. The ratio of storm-time to reference measurements during geomagnetically quiet times adjacent to the storm interval $R\left(\mathrm{O} / \mathrm{N}_{2}\right)=\left([\mathrm{O}] /\left[\mathrm{N}_{2}\right]\right)_{\text {storm }} /$ $\left([\mathrm{O}] /\left[\mathrm{N}_{2}\right]\right)_{\text {quiet }}$ ) proved in general to be near unity (Prölss, 1980; Mikhailov et al., 1995).

However, a positive ionospheric storm effect during daytime is partially caused by the absolute density enhancement of all neutral constituents at fixed heights. For day light conditions enhanced [O] density favours ion production over the loss processes which are enhanced to a lesser degree (see Appendix B of Mikhailov et al., 1995). According to Mikhailov et al. (1995) this is first true for the longitudinal sector where the first storm onset took place at local night time. Different longitudinal sectors, which are marked by the storm onset time, therefore exhibit distinct $F$-layer positive storm mechanisms. 
Finally, nonthermal effects must be taken into account for thermospheric storms, especially during their initial phase. Thermospheric upwelling leads to enriched densities of heavier neutral constituents at higher altitudes whereas downwelling results in their depression and in a relative enrichment of lighter constituents. These vertical transport processes are accompanied by distortions of the barometric height distribution, mainly of the minor gases. They are responsible for nonthermal effects as first reported by Prölss (1982).

\section{The upper atmosphere model simulations}

To test these hypotheses, we performed numerical simulations for the magnetic storm of 24-27 January, 1974, to obtain the global pattern of its thermospheric and ionospheric effects. This storm interval has the advantage that both good neutral gas in situ measurements from the AE-C and ESRO-4 satellites and some plasma observations are available. The neutral gas behaviour of the storm interval was analyzed in detail analytically [e.g. Wei and Förster, 1989).

The geophysical situation is shown in Fig. 1. The storm commencement at 2245 UT on January 24 was followed by a moderate storm which reached its main phase by the end of January 25 with a minimal Dst-value of $-65 \mathrm{nT}$. It is a typical moderate northern winter solstice storm during low solar activity conditions $\left(F_{10.7}=80\right)$.

The global self-consistent model of the thermosphere, ionosphere and protonosphere (GSM TIP) was developed at the Western Department of IZMIRAN (formerly Kaliningrad Observatory) of the Russian Academy of Science (Namgaladze et al., 1988, 1991). For given input data (possibly time dependent) the model calculates the time dependent global threedimensional structure of the temperature, composition $\left(\mathrm{O}_{2}, \mathrm{~N}_{2}, \mathrm{O}\right)$, and vector velocity of the neutral atmosphere and of the densities, temperatures, and vector velocities of atomic $\left(\mathrm{O}^{+}, \mathrm{H}^{+}\right)$and molecular $\left(\mathrm{N}_{2}^{+}, \mathrm{O}_{2}^{+}\right.$, $\mathrm{NO}^{+}$) ions and electrons as well as the two-dimensional distribution of the electric field potential of both dynamo and magnetospheric origin. More recently this model has been modified at the Polar Geophysical Institute in Murmansk and at the Murmansk State Technical University for investigations of high-latitude phenomena. The latitudinal resolution of the model has been increased and the magnetospheric block (code unit) has been incorporated into the model. This block calculates the density, pressure and drift velocity of the hot ions of the magnetospheric plasma sheet as well as the region 2 field-aligned currents (FACs). This Murmansk version of the global model is called the Upper Atmosphere Model (UAM). It has been described in detail by Namgaladze et al. (1998b). Some recent results
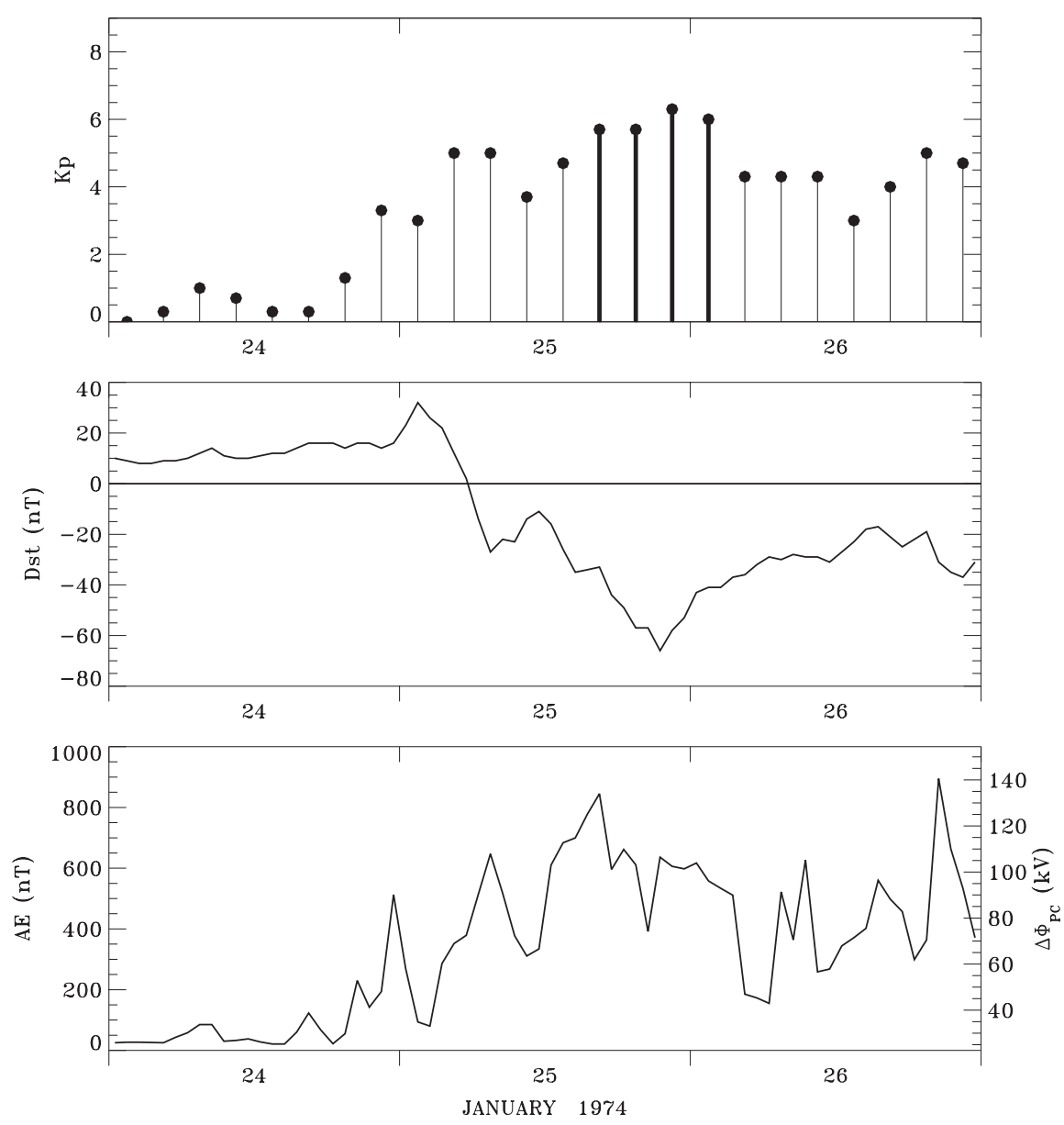

Fig. 1. Geomagnetic activity indices $\mathrm{Kp}$ (upper panel), Dst (middle), and the hourly AE index (bottom, left scale in $\mathrm{nT}$ ) as well as the cross-polar cap potential drop $\Delta \Phi_{P C}$ (right scale, $\mathrm{kV}$ ) estimated from $\mathrm{AE}$ as the model input parameter according to the formula by Weimer et al. (1990) averaged between Northern and Southern Hemispheres versus UT for the time interval 24-26 January, 1974 
obtained by the UAM have been presented by Namgaladze et al. (1996, 1998a, c), Volkov and Namgaladze (1996), Hall et al. (1998), Leontyev et al. (1998) and by Korenkov et al. (1996a, b) with the GSM TIP model variant with the same generic provenance.

In the present study the solution is performed numerically with the UAM on a global grid with a resolution of $2^{\circ}$ in latitude and $15^{\circ}$ in longitude for all thermospheric and ionospheric parameters in a spherical geomagnetic coordinate system. In the vertical dimension, the thermospheric and lower ionospheric code uses 30 grid points between $80-\mathrm{km}$ and $520-\mathrm{km}$ altitude above the Earth's surface. The upper ionospheric part of the code $\left(F_{2}\right.$ region and protonosphere) has variable spatial steps along the geomagnetic field lines from a base altitude of $175 \mathrm{~km}$ to a maximum distance of 15 Earth radii. We assume that the field lines with $L>15(L$ parameter of McIlwain) are open and the field lines with $L \leq 15$ are closed and are electrical equipotentials. The offset between the geographic and geomagnetic axes of the Earth is taken into account. Model inputs are (1) the solar UV and EUV spectra, (2) the precipitating electron fluxes, and (3) the cross-polar cap potential drop $\left(\Delta \Phi_{P C}\right)$.

It has long been clear from the results of simulations with the UAM that upper thermosphere and ionosphere processes are mutually coupled, and it is necessary to model the interaction of the thermosphere-ionosphereplasmasphere processes as a system. In this study, the numerical values of the parameters of the coupled system were calculated for the geophysical conditions of the experiment with the help of the UAM in its complete theoretical variant, i.e., including the thermospheric block to calculate the neutral gas composition, temperature, and dynamics. In this way, all parameters were calculated self-consistently. For the purpose of comparison of theoretical model predictions, the complex model is also run with the empirical MSISE90 model replacing the thermospheric temperature and composition calculations while all other model blocks were kept as before.

To obtain a prestorm reference level, the model was run first for several days under geomagnetically quiet conditions $(K p=1, A p=4.0)$ as were typical for the interval January 22-24, 1974, prior to the storm. The storm day simulation commenced at 0000 UT and was run throughout the whole day with the observed indices of January 25, 1974 as input parameters. The crosspolar potential $\left(\Delta \Phi_{P C}\right)$ is estimated from the hourly AE index according to formula (16) in Weimer et al. (1990), averaged between northern winter and southern summer hemispheres. It serves as the main model input parameter. There is a gradual increase of the energy input in the course of the storm day with several intensifications (near $07 \mathrm{UT}$ and again near $13 \mathrm{UT}$ ) resulting in a maximum of the main phase (as measured by $K_{p}$ and Dst) just prior to midnight (compare Fig. 1). The precipitating $3 \mathrm{keV}$ electron fluxes are taken in proportion to the plasma sheet ion density and normalized to the empirical data of Hardy et al. (1985). The precipitating soft $(0.2 \mathrm{keV})$ electron fluxes are taken into account as well according to Hardy et al. (1985).

\section{Numerical modelling results}

The numerical simulation results of the neutral composition changes agree in general with observations of the AE-C and ESRO-4 satellites and with the MSISE90 model. Figures 2-4 present model results of some important thermospheric parameters while Figs. 5, 6 and 7 illustrate the response of the ionospheric parameters and the neutral wind pattern respectively. The UT variation of some thermospheric and ionospheric parameters for the 12 MLT meridian during the storm day is shown in Fig. 8. It gives a vivid impression of the complex dynamical changes in the disturbed thermosphere and ionosphere during the storm development.

\subsection{Thermospheric constituents}

Figure 2 compares the global neutral oxygen distribution disturbances at four different storm time moments of January 25, $1990(0700,1500,1800$, and 2400 UT from top to bottom). The plots are given in the geomagnetic coordinate system for both the empirical thermospheric MSISE90 model on the left hand side of Fig. 2 and the full theoretical model run on the right side. The Sun's position (circle) and the geographic poles (squares) are shown on the midday-midnight meridian. The other dashed lines indicate the geographic equator and the terminator to illustrate the solar illumination conditions. The colour-coded disturbance level is related to the geomagnetically quiet prestorm day as explained already. It shows the storm to quiet density ratio at the fixed altitude of $300 \mathrm{~km}$.

The differences in the $[\mathrm{O}]$ disturbance pattern development between the MSISE90 predictions (Fig. 2, left side) and the theoretical model run (Fig. 2, right side) are clear. While MSISE90 predicts maximal [O] disturbances near the geographic equator for each of the storm phases shown at different UT moments, the UAM suggests a propagation of the disturbances from auroral latitudes toward the equator in the course of the storm development. Only near the end of the main storm phase do the two [O] disturbance patterns approach similar distributions. The largest positive disturbance amplitudes are recorded in the local time sector between midnight and sunrise, where the theoretical model run reaches slightly larger absolute values (2.4-fold compared with 1.9). Near the auroral zones and above the polar caps the storm time [O] density is diminished with larger absolute disturbance values at the Southern (summer) Hemisphere.

The storm time development of the global molecular nitrogen $\left[\mathrm{N}_{2}\right]$ distribution is presented similarly in Fig. 3. The behaviour of this heavier thermospheric constituent is completely different. Here, the disturbance is confined to high latitudes (larger than $50^{\circ}$ geomagnetic latitude) and the disturbance amplitudes are much larger at the Northern (winter) Hemisphere. This is due to the larger heating efficiency of the auroral Joule heating processes which maximize in the midnight to dawn local time sector. The disturbance amplitude of 

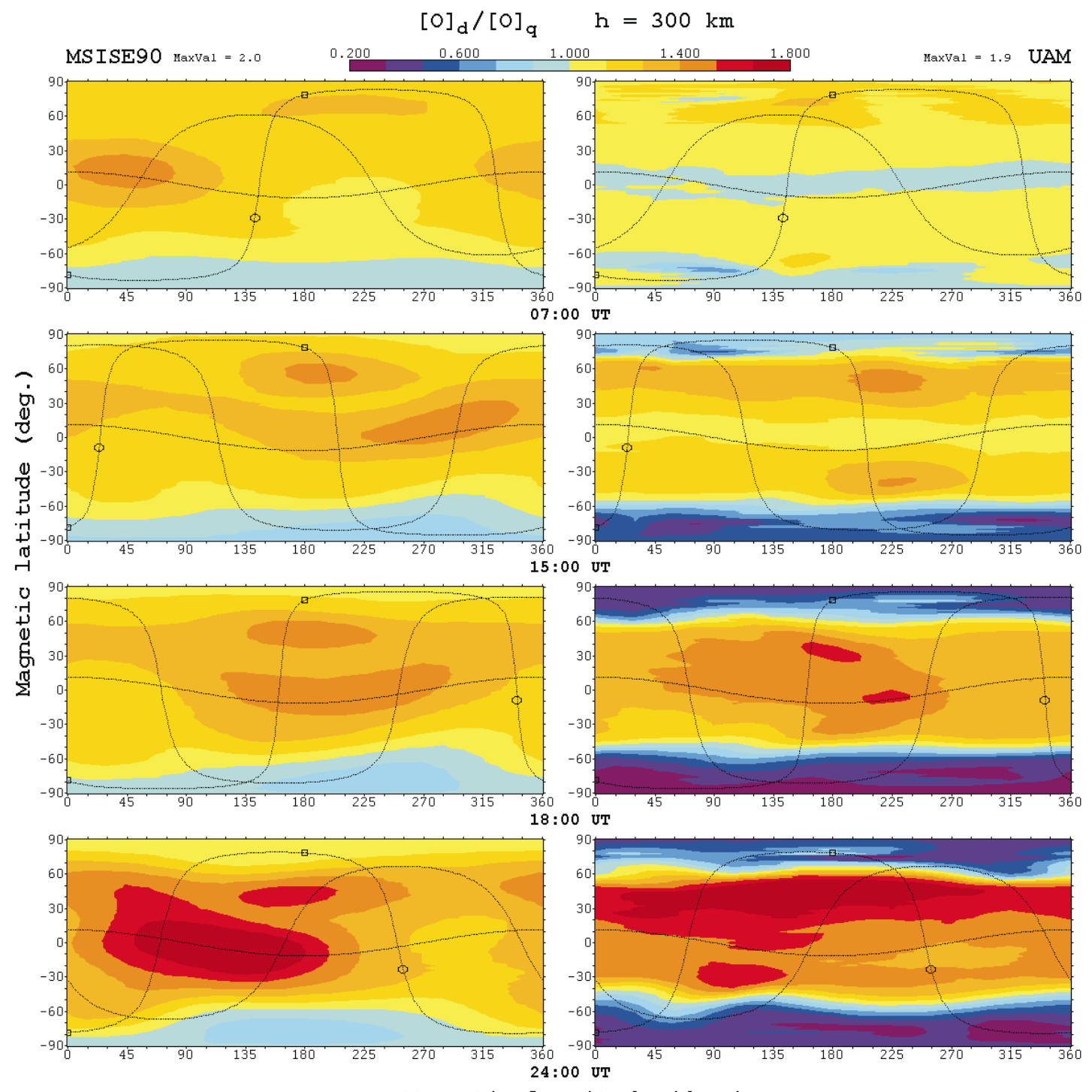

Magnetic longitude

Fig. 2. The geomagnetic maps of the atomic oxygen concentration disturbance (storm to quiet concentration ratio $R(\mathrm{O})=[\mathrm{O}]_{\text {storm }} /$ $[\mathrm{O}]_{\text {quiet }}$ ) at height $300 \mathrm{~km}$ for $0700,1500,1800$ and $2400 \mathrm{UT}$ (from top to bottom) on 25.01.1974 calculated using the empirical thermospheric model MSISE90 (left column) and calculated with the full theoretical Upper Atmosphere Model (right). The Sun position is shown by a

the theoretical model run is about twice as large as for the empirical MSISE90 model.

Figure 4 is a combination of the previous two figures. There are shown the disturbance patterns of the $[\mathrm{O}] /\left[\mathrm{N}_{2}\right]$ ratio in the same manner as before and again at the fixed altitude level of $300 \mathrm{~km}$. This important thermospheric parameter has a strong relationship to ionospheric parameters as it determines to a great extent the photochemical source and loss processes of the ionized particles. The white area indicates a practically unchanged $(\Delta R / R<7.5 \%)$ ratio of the two main thermospheric constituents $\left[\mathrm{N}_{2}\right]$ and $[\mathrm{O}]$ (but not the absence of density changes at all of the individual species). This neutral composition ratio appears to be near (and less than) unity for most mid to low latitude regions. circle together with midday and midnight geographic meridians, the terminator and the geographic equator. The linear colour scale on top of the figure was used for both columns of plots while the actual maxima value of each side are given in the upper left and right corners, respectively

The MSISE90 disturbance values (Fig. 4, left side) and the results of the theoretical model run (Fig. 4, right side) are similar but also exhibit essential differences. First, there is a quantitative discrepancy by a factor of about two with a larger disturbance ratio in the UAM results. But there is also a qualitative difference in that the MSISE90 disturbance pattern seems to develop at all latitudes simultaneously while increasing only in magnitude during the storm day (see Fig. 4, left). The disturbances in the UAM results, on the other hand, develop first near the auroral zones and broaden then toward lower latitudes as the storm intensifies. Their absolute values are generally smaller (up to one order of magnitude) in the Northern (winter) Hemisphere compared with the Southern (summer) Hemisphere, and in the winter hemisphere their equatorward extent is sharply 

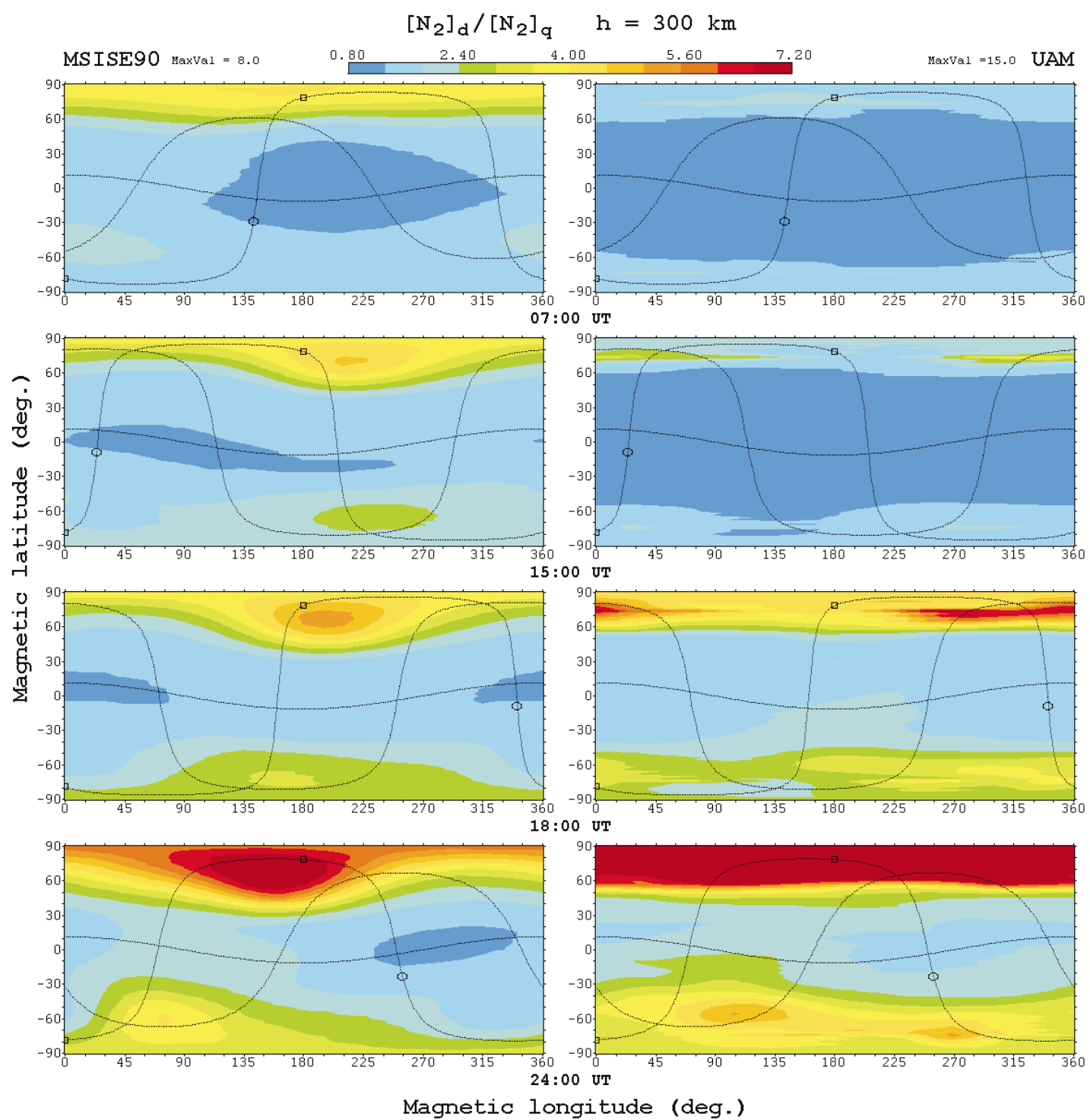

Fig. 3. The same as in Fig. 2 but for the molecular nitrogen concentration disturbance (storm to quiet concentration ratio $R\left(\mathrm{~N}_{2}\right)=\left[\mathrm{N}_{2}\right]_{\text {storm }} /$ $\left.\left[\mathrm{N}_{2}\right]_{\text {quiet }}\right)$

confined to magnetic latitudes larger than about $50^{\circ}$. However, in the summer hemisphere the boundary is less steep, and extends much more equatorward at certain longitudes in the sector between midnight and dawn meridians. All these calculated features are in excellent agreement with averaged ESRO-4 satellite data (Prölss, 1993) and the empirical model of Zuzic et al. (1997).

The perturbation zones of the $[\mathrm{O}] /\left[\mathrm{N}_{2}\right]$ ratio (Prölss, 1981) are generally accepted as the main cause for negative ionospheric storms in the $F_{2}$-layer which are mostly confined to higher latitudes. The northern (winter) perturbation zone resulting from the MSISE90 model is less sharp than those suggested by the theoretical model results and extends to lower magnetic latitudes (down to about $30^{\circ}$, see Fig. 4, left).

\subsection{Ionospheric dynamics}

Figure 5 explores the model results of the ionospheric block of the UAM. It shows electron density distur- bance patterns, i.e., the ratio of electron density during the storm to the geomagnetically quiet reference values. On the left hand side of Fig. 5, the $N_{e}$ disturbance is shown at the fixed height of $300 \mathrm{~km}$ and for the same storm time moments as in Figs. 2-4. The right hand panels present the corresponding disturbance patterns at the $F_{2}$-layer peak height, i.e. the $N_{m} F_{2}$ (disturbed)/ $N_{m} F_{2}$ (quiet) values. Therefore, resulting electron density enhancements (positive storm effects) or depletions (negative storm effects) can directly be compared with the corresponding neutral gas disturbance patterns of the previous figures. During this first storm day (25 January), positive storm effects are more evident in the Northern (winter) Hemisphere than in the Southern (summer) Hemisphere. The $N_{e}$ increases at the fixed altitude of $300 \mathrm{~km}$ (Fig. 5, left side) are more pronounced during local daytime hours but the largest amplitude with a maxima value of 4.0 (as indicated in the upper left corner of the figure) is observed in a thin latitudinal strip near the winter auroral zone. Conversely, 

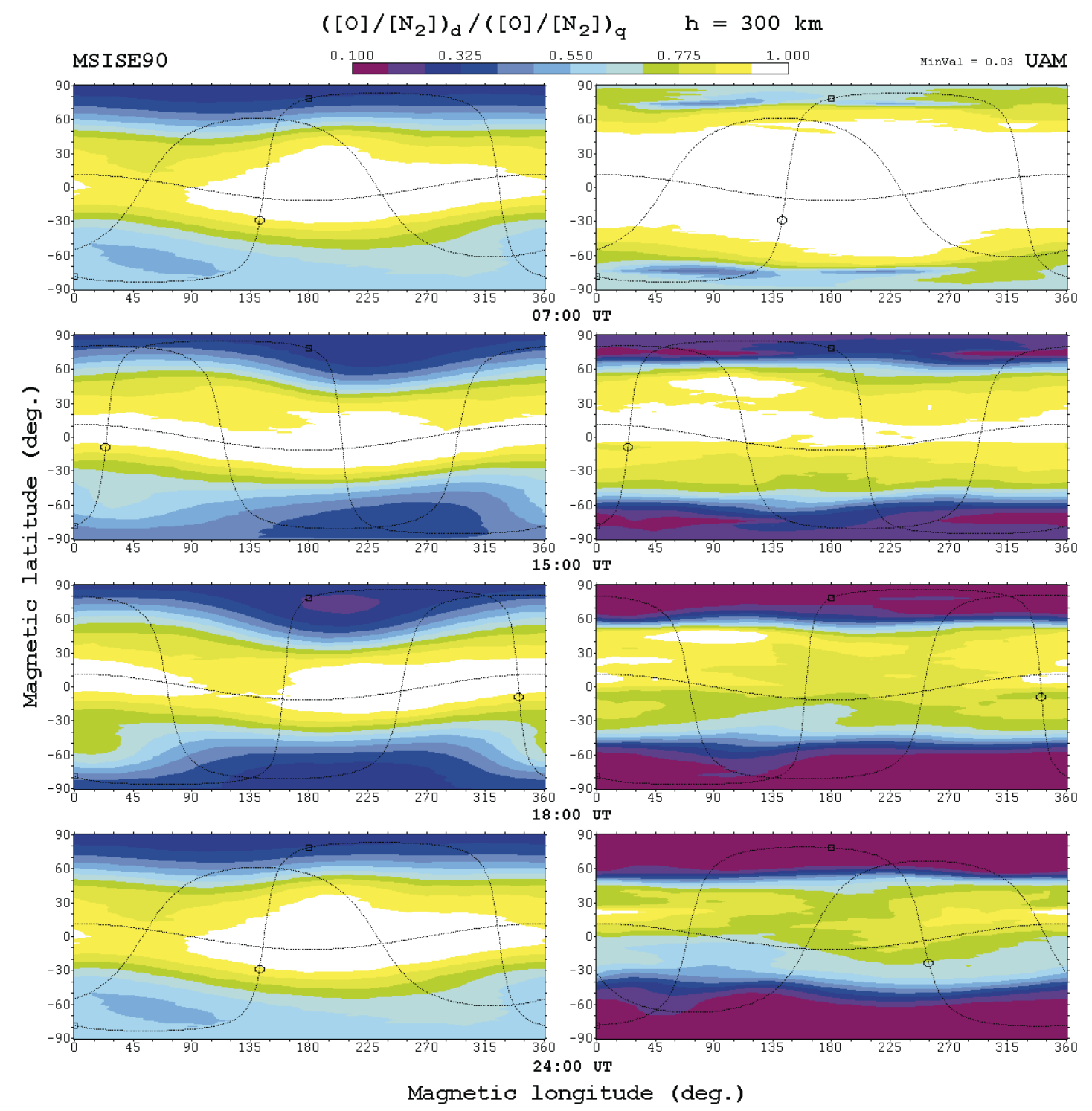

Fig. 4. The same as in Fig. 2 but for the neutral composition disturbance $\left.R\left(\mathrm{O} / \mathrm{N}_{2}\right)=\left([\mathrm{O}] /\left[\mathrm{N}_{2}\right]\right)_{\text {storm }} /\left([\mathrm{O}] /\left[\mathrm{N}_{2}\right]\right)_{\text {quiet }}\right)$

$N_{e}$ depletions predominate at subauroral to midlatitudes, especially during the local nighttime hours of the first storm day.

Ionospheric storm effects are generally referred to the $F_{2}$-layer peak maximum height $\left(h_{m} F_{2}\right)$. Thus we show in the right panels of Fig. 5 the respective $N_{m} F_{2}$ disturbance patterns for the same UT times as for the fixed height plots of the left side. In general, the patterns are quite similar to each other but with some characteristic differences in the amplitudes. The largest positive disturbance amplitudes of $N_{m} F_{2}$ are found during nighttime hours (especially after local midnight) at middle and low latitudes. Negative storm effects are confined to subauroral latitudes at the Northern (winter) Hemisphere (both during daytime and nighttime) and extend toward midlatitudes at the Southern (summer) Hemisphere. Figure 6 gives an additional information about the changes of the $F_{2}$ layer in the course of the storm. The upper panel of Fig. 6 shows the quiet global plot of the $h_{m} F_{2}$ at the beginning of the model run (0000 UT) while the lower panel shows their pattern at the end of the main phase (2400 UT). The quiet daytime $h_{m} F_{2}$ values at midand low-latitudes are about $50 \mathrm{~km}$ below the nighttime ones which are close to our reference level of $300 \mathrm{~km}$ (exept of the equatorial areas near $90^{\circ}$ and $150^{\circ}$ magnetic longitude where $h_{m} F_{2}$ can reach more than $600 \mathrm{~km}$ ). An average uplifting of $h_{m} F_{2}$ by about $50 \mathrm{~km}$ can be observed during storm time. In terms of electron density changes this is more significant for the nighttime mid- to low-latitude ionosphere.

Maximal daytime positive storm effects are seen between $30^{\circ}$ and $50^{\circ}$ magnetic latitude in the winter hemisphere at 1800 UT and 2400 UT (third and fourth panel in Fig. 5), i.e., during the main phase of the storm development.

A more detailed analysis of the relation between negative $F$-region electron density disturbances and the corresponding thermospheric density patterns reveals that they are not exclusively correlated with the neutral composition behaviour. They are influenced by electron 

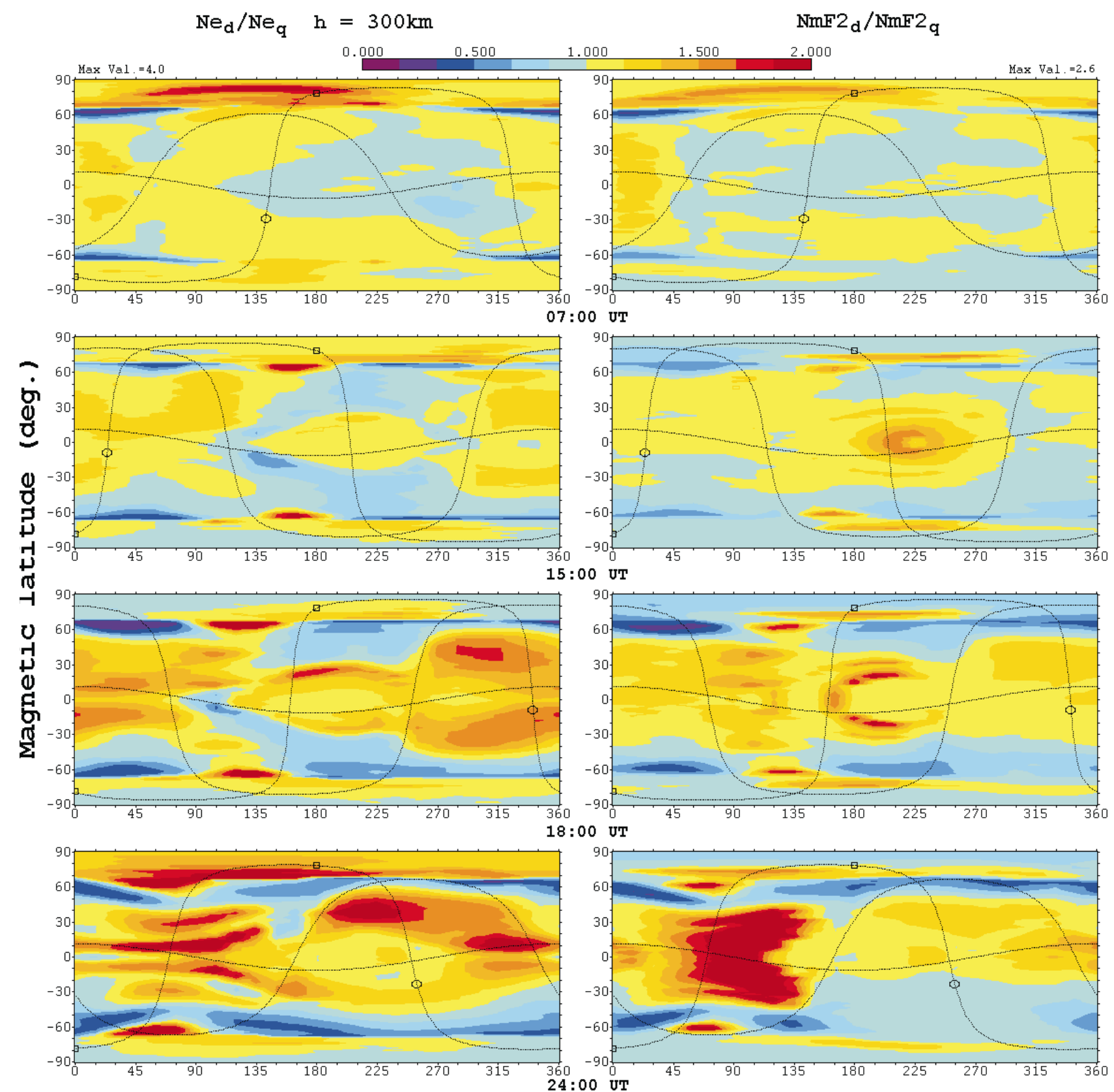

Magnetic longitude (deg.)

Fig. 5. The electron concentration disturbance patterns (storm to quiet concentration ratio) for the same moments of UT as in Figs. 2, 3 and 4 . On the left they are shown with respect to the same fixed height of $300 \mathrm{~km}$ as in the previous figures while the right side panels show

precipitation and electromagnetic ion drift effects (ion transport and heating) at higher latitudes mainly in the Northern winter Hemisphere. By the end of the first storm day a negative storm phase is developing at middle and low latitudes of the Southern Hemisphere during local daytime hours (bottom panel in Fig. 5).

Positive ionospheric storms are often related to the action of disturbed meridional neutral wind. To investigate this, Fig. 7 shows the corresponding disturbance neutral wind pattern (i.e., the difference between the storm and quiet time values) for the same storm time the corresponding density ratios at the $F_{2}$ layer peak height $\left(N_{m} F_{2}\right)$. The linear colour scale on top indicates the disturbance level: positive storm effects are shown with yellow to red colours while negative effects are represented by blue to grey ones

moments as in the previous figures. The largest amplitudes of the disturbance neutral wind are found within the auroral zones in the evening sector. There the neutral winds are strongly westward directed as a consequence of the strong coupling with the storm-time magnetospheric convection pattern which has its sunward directed return flow at auroral and subauroral latitudes. The coupling between the neutral gas and the plasma component is most intense in the afternoon to evening sector due to the high plasma density and the supporting action of the neutral gas corotation with the 


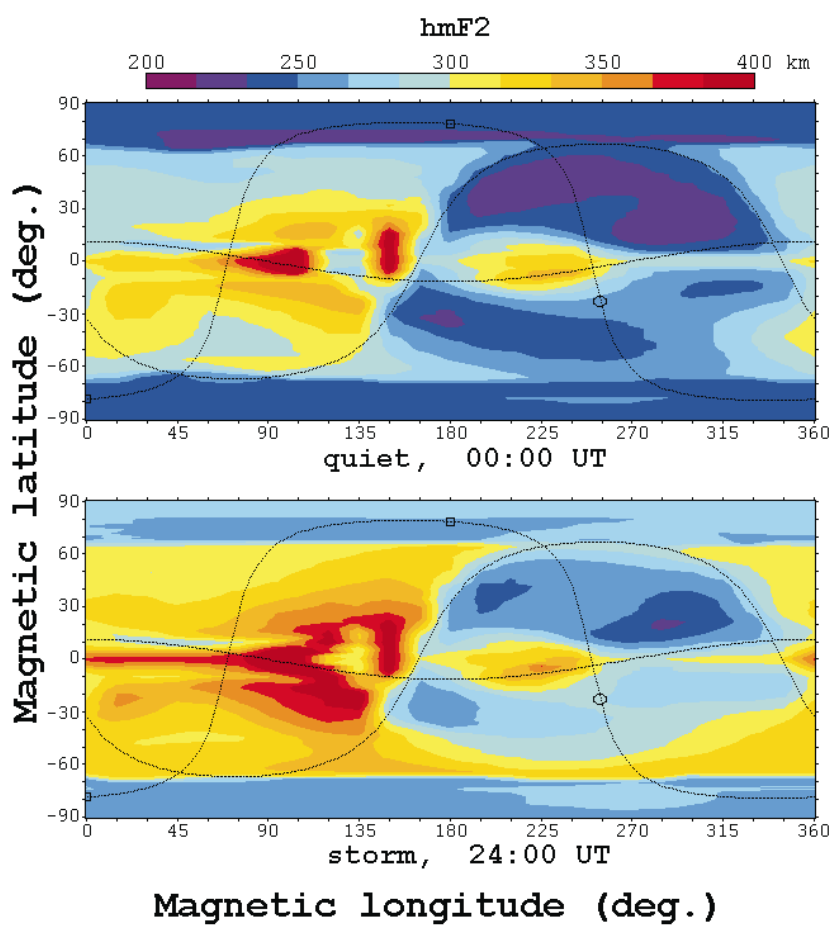

Fig. 6. Peak height of the $F_{2}$ layer $\left(h_{m} F_{2}\right)$ at 2400 UT for quiet (upper panel) and disturbed (lower panel) conditions at the start and the end of the modelled day, respectively

Earth. The zonal disturbance wind amplitude in general exceeds the meridional component by a considerable amount and reaches about $500 \mathrm{~m} \mathrm{~s}^{-1}$ in our case. The meridional disturbance wind is less by a factor of about 3 to 5 and is mostly directed equatorward, i.e. away from the auroral heating zones, as could be expected. It is modified only by the action of the Coriolis force.

\subsection{Temporal variations}

The global dynamical response of the thermosphere and ionosphere to magnetospheric forcings is illustrated in Fig. 8 for the 1200 MLT meridian. Neutral mass density variations (upper panel) and neutral temperature changes (second panel) versus UT of the storm day are shown at the fixed altitude level of $300 \mathrm{~km}$.

Every increase of magnetospheric energy input which manifests itself in a rapid enhancement of the cross polar cap potential triggers the generation of atmospheric gravity waves in the auroral zones. It is due to enhanced particle precipitation fluxes and an intensification of the auroral current systems and their dissipation (Joule heating) at high latitudes. In Fig. 8 this can be observed at 07 UT and again at 13 UT. The waves from both hemispheres propagate toward the equator and arrive there with a characteristic time delay of about $4 \mathrm{~h}$. This corresponds to a wave velocity of about $580 \mathrm{~m} \mathrm{~s}^{-1}$ which is characteristic for gravity waves Prölss (1997).

The relative density enhancement has its maximal value at the end of the main phase of the storm, when the density enhancement comprises the whole globe.

The neutral temperature disturbance pattern is quite different from the density pattern. Here, the largest
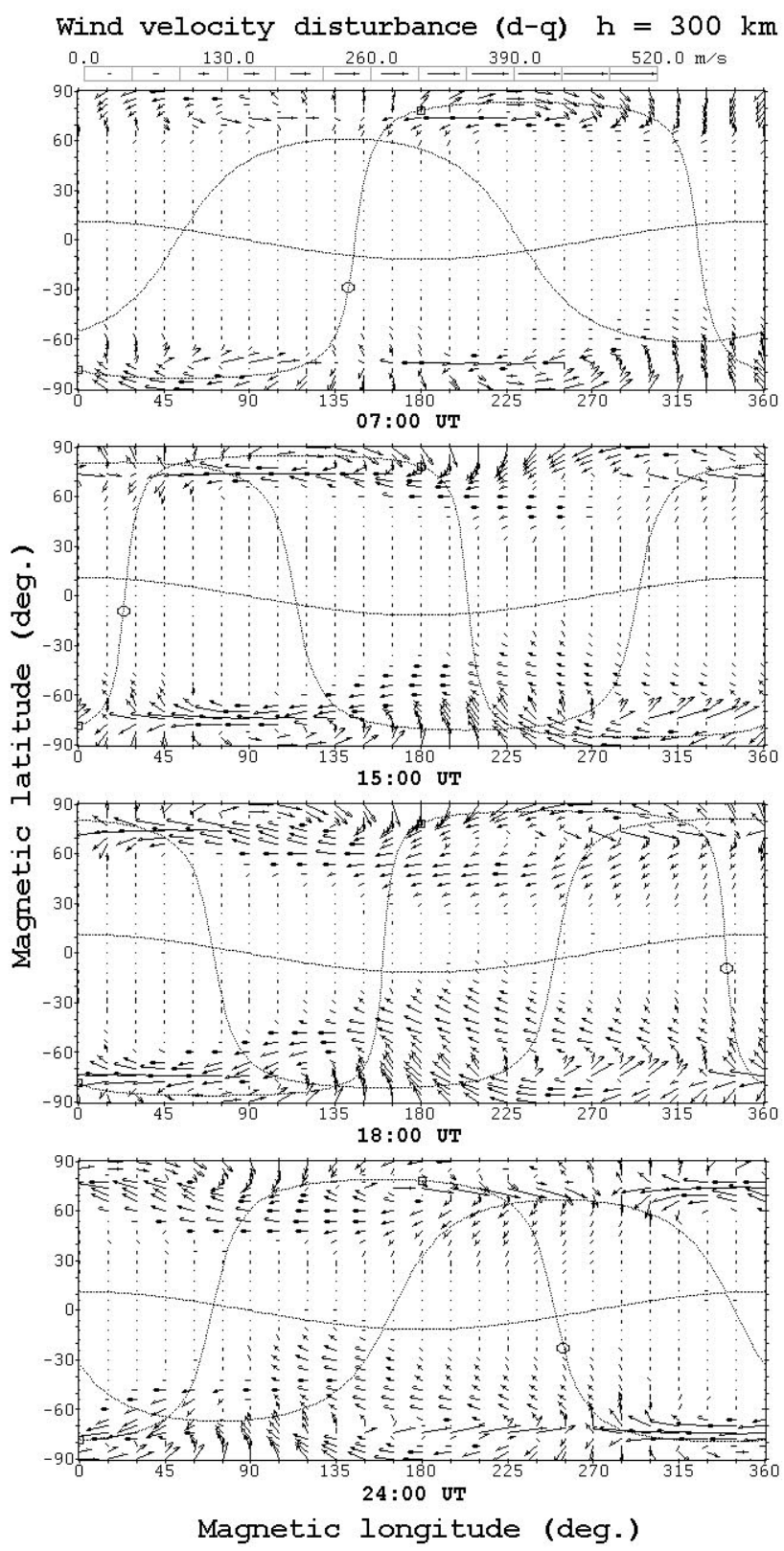

Fig. 7. The same as in Fig. 5 but for the horizontal thermospheric wind disturbance (storm minus quiet velocity, $\mathrm{m} \mathrm{s}^{-1}$ )

relative temperature enhancements occur at high latitudes near the auroral ovals, increasing in magnitude with storm time. The latitudinal gradient of the neutral disturbance temperature toward mid and low latitudes is quite steep in the Northern (winter) Hemisphere and is located near about $60^{\circ}$ magnetic latitude while in the Southern (summer) Hemisphere it is smooth and extends to lower latitudes (second panel of Fig. 8).

The third panel of Fig. 8 shows the storm-time development of neutral composition changes. The neutral composition ratio $R$ is larger, and its gradient greater, in the winter hemisphere than in the summer hemisphere, suggesting the gradual expansion of the neutral composition disturbance zones toward mid latitudes during the rising storm activity with wellknown seasonal differences in amplitude and extent. The 


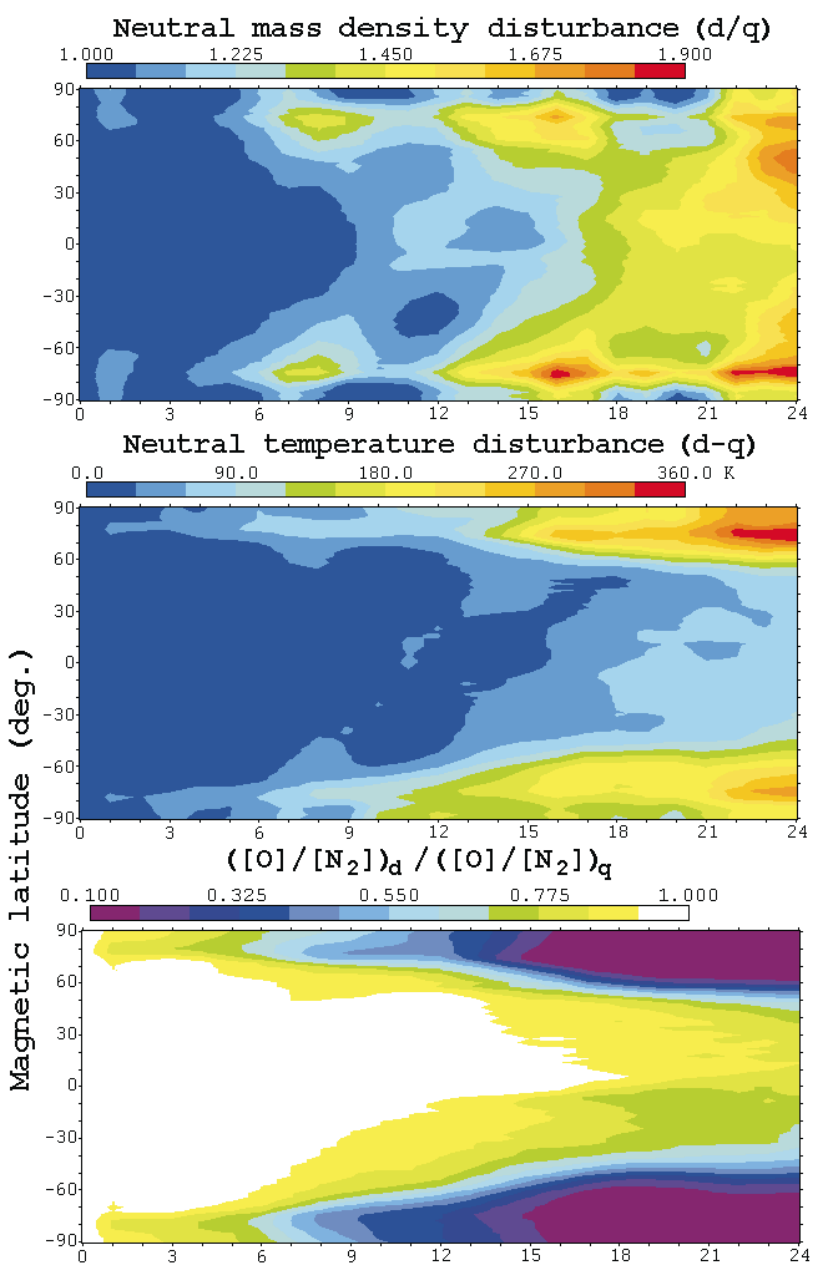

$\operatorname{NmF} 2(d / q)$ and wind velocity (d-q) disturbances

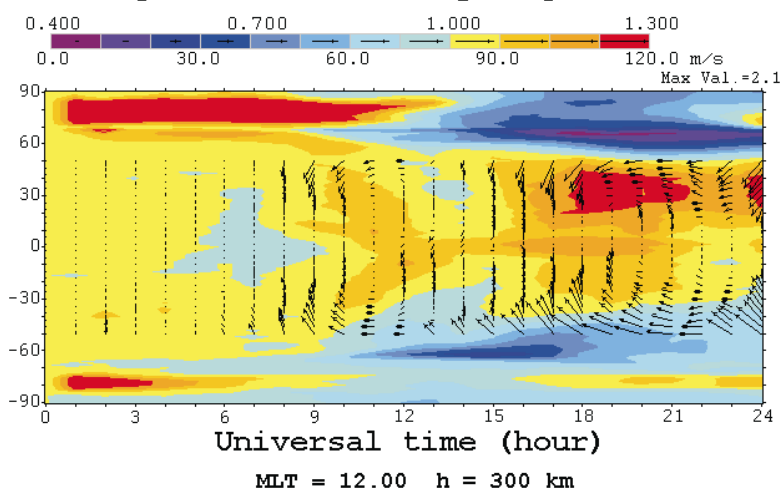

Fig. 8. The storm time evolution of the neutral mass density disturbance (storm to quiet density ratio, upper panel) and of the neutral temperature disturbance (storm minus quiet temperature, $\mathrm{K}$, second panel) for $1200 \mathrm{MLT}$ at an altitude of $300 \mathrm{~km}$. The third panel shows similarly to Fig. 4 the temporal development of the neutral composition disturbance (storm to quiet ratio of $[\mathrm{O}] /\left[\mathrm{N}_{2}\right]$ ), while the bottom panel presents the electron density disturbance at the $F_{2}$-layer maximum ( $N_{m} F_{2}$, storm to quiet density ratio) at the background of the horizontal thermospheric wind disturbance (storm minus quiet velocity, $\mathrm{m} / \mathrm{s}$ ) for magnetic latitudes $<50^{\circ}$ only for clarity reasons. The arrow length indicates the wind amplitude as shown in the colour bar of the $N_{m} F_{2}$ disturbance ratio above

maximal disturbance values are found near the northern auroral zone at 2400 UT (end of the main storm phase) and are less than $1 / 10$ th of the quiet time reference. The equatorward disturbance zone boundary at this time is located between $50^{\circ}$ and $60^{\circ} \mathrm{N}$ magnetic latitude and correspondingly we find a quite strong negative electron density storm phase inside the disturbance zone on the winter hemisphere developing after about 1400 UT in parallel to the expansion of the disturbance zone. The composition disturbance boundary at the Southern summer Hemisphere is dragged down to about $40^{\circ}$ magnetic latitude and the absolute values of $R$ are relatively small.

Equatorward of the disturbances zones, there is a broad latitudinal stripe with an apparent undisturbed composition ratio $(R=1)$ or values slightly below unity (for fixed altitudes). The corresponding electron density variation at the $F_{2}$ maximum shown in the bottom panel of Fig. 8 nevertheless reveals a distinct positive electron density disturbance at these latitudes. It develops over many hours beginning at $0700 \mathrm{UT}$ with the first launching of TADs approaching the equator from both hemispheres at about 1100 UT. With the second storm intensification at about 1300 UT the positive ionospheric storm phase is at maximum, especially in the Northern (winter) Hemisphere, and persists for several hours with electron density values which are up to twice as large as the undisturbed reference values. In the Southern (summer) Hemisphere a positive storm phase is also present but is less intense. It disappears there around 2000 UT and is followed by a weak negative ionospheric storm phase (bottom panel of Fig. 8).

The largest disturbance wind amplitudes at midlatitudes are achieved in the Southern Hemisphere during the various successive storm intensifications (see the mid- to low-latitude disturbance wind pattern overlayed at the bottom panel). It is evident from this figure that the short-term (of the order of several hours) $F_{2}$ layer density increase (decrease) follows the equatorward (poleward) turning of the thermospheric disturbance wind with a time lag of 1-2 hours.

The disturbance wind pattern at the heights of the dynamo-region lead to disturbance dynamo electric fields which in turn have a feedback on the plasma density and the neutral wind dynamics (Fejer and Scherliess, 1995). The magnetospheric electric fields can also partly penetrate to low latitudes during the magnetic storm. The next Fig. 9 shows the calculated storm time variation of the zonal electric field (positive eastward) disturbance at the 1200 MLT meridian at magnetic latitudes less than $70^{\circ}$. Blue colours correspond to downward plasma drifts and, correspondingly, to negative ionospheric disturbances; yellow-red colours correspond to the uplifting of the plasma and positive ionospheric disturbances, except in the equatorial anomaly region where the upward plasma drift decreases the electron density at the magnetic equator and increases it in the "crests" of the anomaly ("fountain" effect). We can see that at low latitudes, during daytime after $0800 \mathrm{UT}$, the electric disturbance field helps to create positive ionospheric disturbances whereas at latitudes higher than $40^{\circ}$ it supports negative ionospheric disturbances. The latitude of the boundary between these positive and negative electric field effects moves 


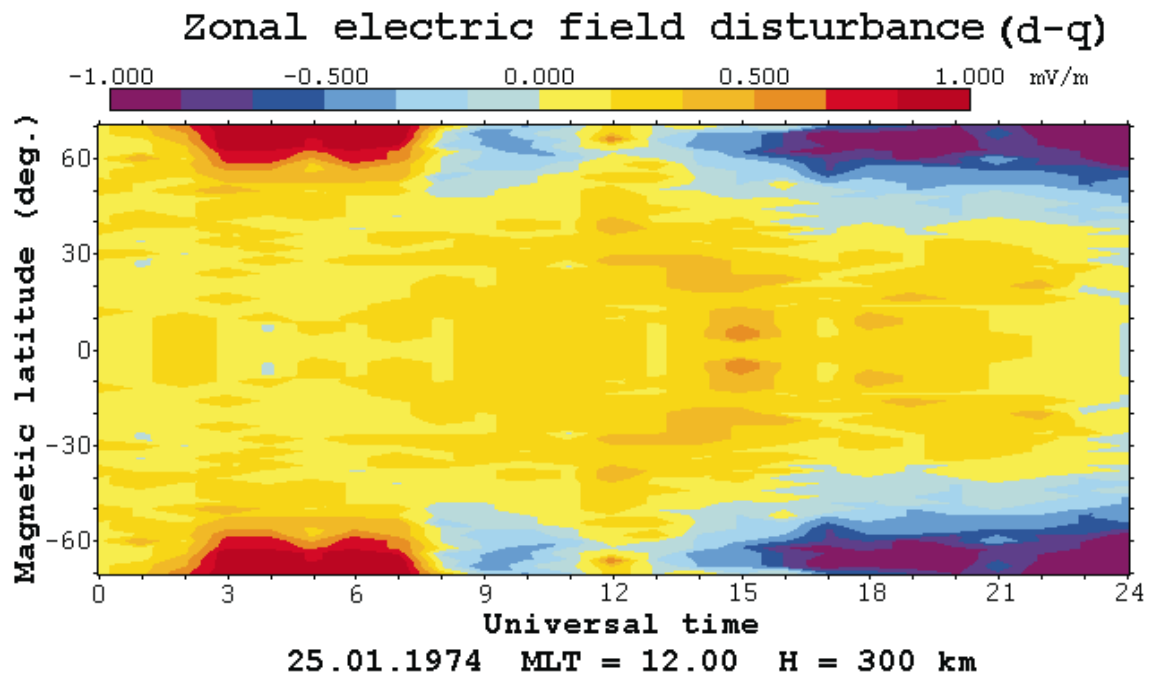

Fig. 9. The storm time evolution of the zonal component of the electric disturbance field (storm minus quiet field values, $\mathrm{mV} \mathrm{m}^{-1}$ ) for 1200 MLT at an altitude of $300 \mathrm{~km}$. The magnetic latitude range is confined to $\pm 70^{\circ}$ to show mid and low latitude effects equatorwards during the storm development. However, the electric field disturbances on the daytime side are small at mid and low latitudes. The $1 \mathrm{mV} \mathrm{m}^{-1}$ corresponds to a vertical drift velocity of $\sim 40 \mathrm{~m} \mathrm{~s}^{-1}$ at the magnetic equator and this velocity decreases proportional to $\cos I$ ( $I$ is the inclination of the magnetic field lines) with increasing latitude.

Figure 10a, b presents for two different times (1250 UT and 2133 UT) a direct comparison of our modelled composition variations (solid curves) with satellite measurements from AE-C (dashed), the ESRO4 empirical model of Zuzic et al. (1997) (dotted) and the MSISE90 model (open circles). The ESRO-4 model data reflect a longitudinally averaged behaviour and are for a slightly different altitude $(280 \mathrm{~km})$. The meridional profiles are shown along the AE-C orbits at the indicated local times (both at local afternoon) and geodetic longitudes. The correspondence between the modelled meridional composition variation and the measurement is quite good. It reproduces appropriately the meridional gradients of the disturbance zone boundaries and their absolute values. The meridional profiles of the MSISE90 model obviously fail to reproduce the steepness of these gradients. This is presumably the result of statistical averaging of many individual storm periods during the construction of the empirical model as a polynomial series; it smears out any sharp boundary. The empirical model of Zuzic et al. (1997) based on an averaged model of ESRO-4 data which takes into account the disturbance boundary location with respect to magnetic latitudes is closer to the UAM results. Skoblin and Förster (1995) showed that the perturbation zone boundary is especially steep for winter conditions due to favourable conditions of horizontal and vertical transport in comparison with the relaxation time of $[\mathrm{O}] /\left[\mathrm{N}_{2}\right]$ perturbations.

At mid and low latitudes both the measurements and our model curves show values close to or slightly below unity at fixed height. According to Burns et al. (1995a) it is just this local time sector (winter afternoon) which should reveal values of $R>1$. This cannot be confirmed by our model calculations nor by the measurements shown.

The two bottom panels (Fig. 10c, d) give the corresponding model $N_{e}$ variations as the storm to quiet ratios at $250 \mathrm{~km}$ altitude for the same meridional cuts. Table 1 lists, for comparison, ionosonde observations approximately along the orbital traces of the two AE-C orbits. The $N_{m} F_{2}$ ratios are calculated as average value of the two nearest hourly values at the storm day with respect to the corresponding monthly medians at these two hours. Unfortunately, there are only a few ionosonde stations available in the Southern summer Hemisphere.

The correspondence between the observed meridional profile of the storm-to-quiet electron density ratio at the $F_{2}$-layer maximum with the modelled values (solid lines in Fig. 10c, d) is quite good. Outside the disturbance zones at higher latitudes the electron density indicates positive storm phases at both local times while within them the "classical" negative phases are correlated with the $R$ parameter as expected. The positive phase at mid and low latitudes is more pronounced in the Northern (winter) Hemisphere and has larger amplitudes at the later time (2133 UT). The latter could be due to the stonger, advanced storm phase or to longitudinal differences, while the former fact suggests an explanation for the positive effect. Comparing the upper and the lower panels, compositional changes are obviously not responsible. The positive phases are due mainly to changes of the global wind circulation (see Fig. 8, bottom panel) which results in an enlarged equatorward directed meridional wind component during the main phase of the storm.

\section{Discussion}

\subsection{Thermospheric composition}

Although the density ratio $[\mathrm{O}] /\left[\mathrm{N}_{2}\right]$ for the storm maximum decreases by more than a factor of 10 in 


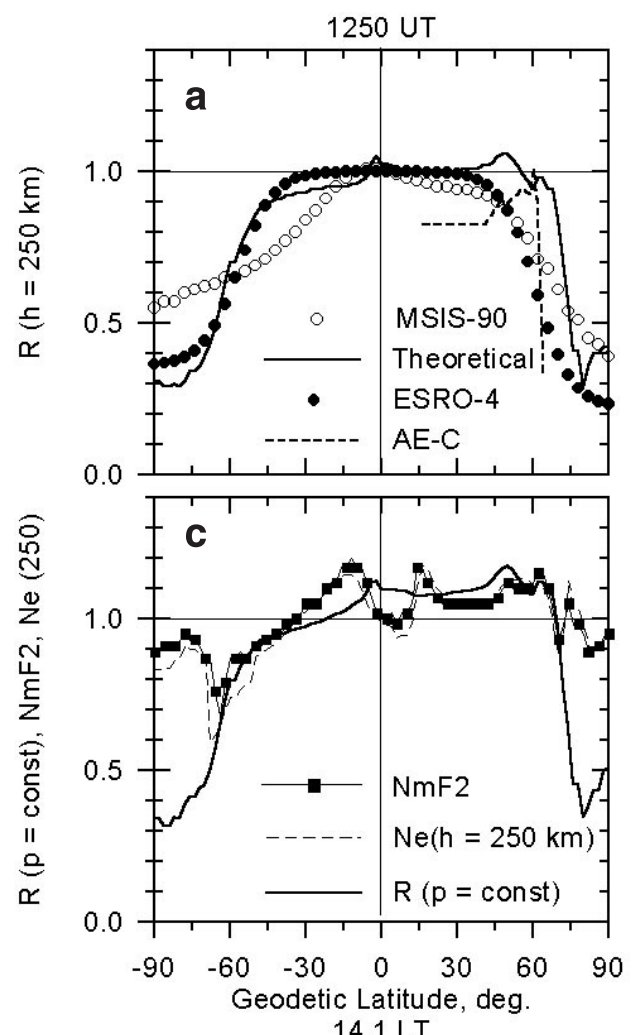

14.1 LT

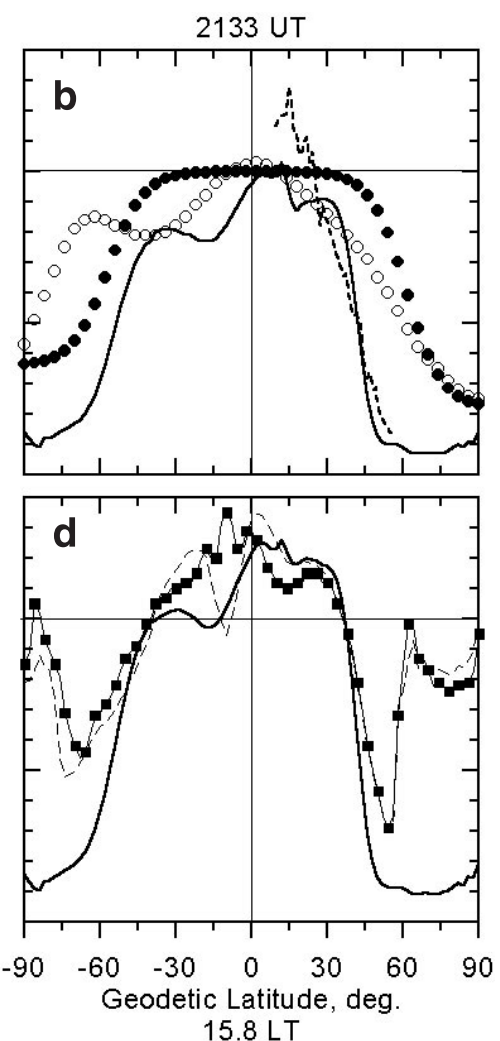

$15.8 \mathrm{LT}$
Fig. 10a-d. The thermospheric composition ratio (solid lines) $R\left(\mathrm{O} / \mathrm{N}_{2}\right)$ is shown both for a fixed altitude of $250 \mathrm{~km} \mathrm{(a,} \mathrm{b)} \mathrm{and} \mathrm{for} \mathrm{a}$ near constant pressure level at $1.3 \times 10^{-5} \mathrm{~Pa}$ $(\mathbf{c}, \mathbf{d})$. Comparison with observations (upper panels) is made for two different UT according to AE-C satellite overflights at local afternoon near $4.1 \mathrm{LT}\left(19^{\circ} \mathrm{E}\right)$ or $1250 \mathrm{UT}$, and b $15.8 \mathrm{LT}\left(273^{\circ} \mathrm{E}\right)$ or 2133 UT. Shown are corresponding MSISE90 model values (open circles) and the AE-C measurements (dashed lines) reduced to $250 \mathrm{~km}$ altitude while ESRO-4 data according to the statistical model of Zuzic et al. (1997) are at $280 \mathrm{~km}$ (solid circles). c, d. This shows the modelled stormto-quiet ratios of electron density at $250 \mathrm{~km}$ altitude (dashed) and at the $F_{2}$-layer maximum $\left(N_{m} F_{2}\right.$, full squares) (taken from Förster et al., 1999) comparison with the quiet time reference level at high latitudes, at low to middle latitudes it does not decrease (at fixed altitudes) below the quiet level. This result arises from our model calculations for a moderate northern winter solstice storm at low solar activity (Fig. 4, right side, and Fig. 8, third panel).

The direct comparison of our model results with two different AE-C orbits during the storm and with ESRO4 measurements sumarized in an empirical model of Zuzic et al. (1997) confirms this conclusion. Moreover, even the latitudinal profiles taken from the global empirical neutral gas model MSIS90E verify this fact despite failing to reproduce the steep latitudinal gradient at the transition to the disturbance region at higher latitudes (see Fig. 10a, b). The same result is confirmed by numerous satellite observations of thermospheric composition at low to middle latitudes (Hedin et al., 1977; Prölss, 1982; Burrage et al., 1992; Burns and Killeen, 1992; Burns et al., 1995b) as well as closer examination of $[\mathrm{O}]$ density by ground-based incoherent scatter and Fabry-Perrot measurements (Burnside et al., 1991). They show that the thermospheric response to a geomagnetic storm at low to middle latitudes consists of a quite moderate density increase of all atmospheric constituents, while the ratio $R\left([\mathrm{O}] /\left[\mathrm{N}_{2}\right]\right)$ remains around unity.

However, this is contrary to the predictions obtained in some recent storm modelling studies using major thermospheric general circulation models (Rishbeth et al., 1987; Crowley et al., 1989; Fuller-Rowell et al., 1991, 1994). This conflicting result is also discussed by Burns et al. (1995a, b). In their modelling study of the geomagnetic storm on November 24, 1982, Burns et al. (1995a) have a $20 \%$ to $50 \%$ change in the $[\mathrm{O}] /\left[\mathrm{N}_{2}\right]$ ratio between storm and quiet time at low and middle latitudes (at fixed altitudes, see their Fig. 2). For a small band some $10^{\circ}$ latitude wide in the evening to midnight sector of the mid-latitude winter hemisphere just adjacent to the disturbance region they even find a $80-90 \%$ enhancement in the $[\mathrm{O}] /\left[\mathrm{N}_{2}\right]$ ratio.

Rishbeth (1998) discusses the question of how the thermospheric circulation affects the thermospheric composition and consequently the ionospheric $F_{2}$-layer densities. A modelling study by Rishbeth and MüllerWodarg (1999) on geomagnetically quiet global circulation and thermospheric composition effects using the coupled thermosphere-ionosphere-plasmasphere model CTIP (Fuller-Rowell et al., 1996; Millward et al., 1996; Field et al., 1998) shows that large $\left[\mathrm{O} / \mathrm{N}_{2}\right]$ ratios are formed in the winter high (subauroral) latitudes, especially in "far-from-pole" areas (e.g. around geographic latitudes $70^{\circ}-80^{\circ} \mathrm{N}$ at $90^{\circ} \mathrm{E}$ for northern winter solstice). These are regions of strong downwelling within the global thermospheric seasonal circulation from the summer to winter hemisphere due to the sparse energy input there (not sunlit in winter). Rishbeth and MüllerWodarg (1999) argue that horizontal wind smoothes out these $\left[\mathrm{O} / \mathrm{N}_{2}\right]$ maxima. During storm time, both the horizontal and the vertical transport is enlarged and the resulting effect for the composition ratio change $R(\mathrm{O} /$ $\mathrm{N}_{2}$ ) seems to level in accordance with our modelling results.

The large increase of $R\left(\mathrm{O} / \mathrm{N}_{2}\right)$ in the storm-perturbed thermosphere discussed by Burns et al. (1995a) could 
Table 1. Ionosonde observations near AE-C overflights at $1250 \mathrm{UT}$ and 2133 UT respectively

\begin{tabular}{|c|c|c|c|}
\hline $\begin{array}{l}\text { Ionosonde } \\
\text { Station }\end{array}$ & $\begin{array}{l}\text { Geodetic } \\
\text { longitude }\end{array}$ & $\begin{array}{l}\text { Geodetic } \\
\text { latitude }\end{array}$ & $\frac{N_{m} F_{2}^{\text {storm }}}{N_{m} F_{2}}$ \\
\hline \multicolumn{4}{|c|}{$\begin{array}{l}25 \text { January } 1974,1200-1300 \text { UT AE-C orbit } \\
\text { at } \sim 19^{\circ} \mathrm{E} \text { or } \sim 14.1 \text { hours LT }\end{array}$} \\
\hline Loparskaya & 33.0 & 68.0 & 1.828 \\
\hline Kiruna & 20.4 & 67.8 & 1.989 \\
\hline Sodankyla & 26.6 & 67.4 & 1.939 \\
\hline Lycksele & 18.8 & 64.7 & 1.357 \\
\hline Arkhangelsk & 40.5 & 64.4 & 1.402 \\
\hline Nurmijarvi & 24.6 & 60.5 & 1.401 \\
\hline Leningrad & 30.7 & 60.0 & 1.217 \\
\hline Uppsala & 17.6 & 59.8 & 1.268 \\
\hline Moscow & 37.3 & 55.5 & 1.361 \\
\hline Kaliningrad & 20.6 & 54.7 & 1.110 \\
\hline Juliusruh/Rügen & 13.4 & 54.6 & 1.206 \\
\hline Miedzeszyn & 21.2 & 52.2 & 1.181 \\
\hline De Bilt & 5.2 & 52.1 & 1.106 \\
\hline Lindau & 10.1 & 51.6 & 1.053 \\
\hline Kiev & 30.5 & 50.5 & 1.055 \\
\hline Dourbes & 4.6 & 50.1 & 0.850 \\
\hline Freiburg & 7.6 & 48.1 & 1.035 \\
\hline Bekescsaba & 21.2 & 46.7 & 1.087 \\
\hline Poitiers & 0.3 & 46.6 & 0.967 \\
\hline Sofia & 23.4 & 42.7 & 0.967 \\
\hline Athens & 23.6 & 38.0 & 1.035 \\
\hline Johannesburg & 28.1 & -26.1 & 1.124 \\
\hline Hermanus & 19.2 & -34.4 & 1.263 \\
\hline Syowa Base & 39.6 & -69.0 & 0.752 \\
\hline \multicolumn{4}{|c|}{$\begin{array}{l}25 \text { January } 1974,2100-2200 \text { UT, AE-C orbit } \\
\text { at } \sim 273^{\circ} \mathrm{E} \text { or } \sim 15.8 \text { hours LT }\end{array}$} \\
\hline Resolute Bay & 265.1 & 74.7 & 0.899 \\
\hline Churchill & 265.8 & 58.8 & 0.183 \\
\hline Winnipeg & 265.6 & 49.8 & 0.276 \\
\hline Ottawa & 284.1 & 45.4 & 0.470 \\
\hline Boulder & 254.7 & 40.0 & 0.489 \\
\hline Wallops Island & 284.5 & 37.8 & 0.807 \\
\hline Huancayo & 284.7 & -12.0 & 1.591 \\
\hline Conception & 287.0 & -36.6 & 0.704 \\
\hline
\end{tabular}

also be a specific phenomenon due to high solar activity or because of the extremely strong storm conditions of their case study. These enhancements of the $\mathrm{O} / \mathrm{N}_{2}$ ratio were found to occur immediately adjacent to a region of strong $\mathrm{O} / \mathrm{N}_{2}$ decrease and is very narrow (about $10^{\circ}$ ). Only two cases have thus far been shown which represent two succeeding orbits during an extremely strong and extended disturbance period (Burns et al., 1995a).

Zuzic et al. (1997) mentioned that the $[\mathrm{O}] /\left[\mathrm{N}_{2}\right]$ increases as discussed by Burns et al. (1995a) may not be a salient feature of the disturbed thermosphere. Prölss et al. (1998) repeated the magnetic storm modelling of December 8, 1992 (Burns et al., 1995b) using both the TIGCM and the CTIM. They compared both simulations with neutral gas measurements of the Dynamics Explorer 2 satellite and found that both models significantly overestimate the increase in the $\mathrm{O} / \mathrm{N}_{2}$ density ratio at mid and low latitudes (on a constant pressure surface). Similarly, both models predict ionization density increases in the regions of predicted $\mathrm{O} / \mathrm{N}_{2}$ ratio increase which are far from those positive storm effects really observed there by ionosondes (Prölss et al., 1998).
Nowhere at $300 \mathrm{~km}$ did we find values of $R(\mathrm{O} /$ $\left.\mathrm{N}_{2}\right) \geq 1$ (see Figs. 4 and 8, third panel). Furthermore, variations of less than $10 \%$ must be considered within numerical uncertainty.

The AE-C measurements in Fig. 10b slightly exceed unity near $15^{\circ}$ geodetic latitude, but this is insignificant. Skoblin and Mikhailov (1996) have studied the low to mid latitude ratio $R\left(\mathrm{~N}_{2} / \mathrm{O}\right)$ using all available data of ESRO-4. They applied a special method to minimize the errors of data reduction and found no cases of storm time drop of the $\mathrm{N}_{2} / \mathrm{O}$ ratio below unity (i.e., $\mathrm{O} / \mathrm{N}_{2}$ above 1.0). On the contrary, there are some hints that a slight decrease of $R\left(\mathrm{O} / \mathrm{N}_{2}\right)$ takes place at fixed height at low latitudes, but no increase.

\subsection{Dynamic storm development}

The storm time neutral gas redistribution is a very dynamic process. This is the most obvious result of the comprehensive, time dependent model runs. It is effected by the generation of large-scale gravity waves in the auroral heating zones (see Fig. 8) and the transition to a storm time global neutral gas circulation which differs significantly from the geomagnetically quiet pattern (Fig. 7). Further, it comprises general (global) but locally different neutral temperature and density enhancements (Fig. 8), and finally a thermospheric composition change at high to middle latitudes but no significant change of composition at low to middle latitudes, as was discussed in Subsect. 5.1.

The thermospheric dynamic processes are illustrated in Figs. 2-4 and 7-8 and compared with storm developments resulting from the use of the empirical MSIS90E model in storm modelling. The results of our theoretical model calculations are as follows. The disturbance of the atomic oxygen concentration differs significantly from MSISE90 at the earlier stages of the magnetic storm but it tends to approach the MSISE90 distribution during the storm development (Fig. 2). MSISE90 gives a maximum of the [O] disturbance near the geographic equator at every UT moment whereas in our numerical modelling the disturbance propagates from auroral latitudes toward the equator. Therefore, numerical simulations which make use of the MSISE90 empirical neutral gas model produce static, intermediate frozen states which do not correspond to the real dynamic behaviour of the thermosphere. Only later in the magnetic storm development at the end of the main storm phase do the two disturbance patterns (MSISE90 and full theoretical model run) converge (see Fig. 2 left and right side, respectively).

The disturbance of molecular nitrogen is confined to high latitudes (more than $50^{\circ}$ geomagnetic latitude) being larger in the winter hemisphere both in the MSISE90 empirical model, and much larger in our theoretical model calculations (Fig. 3). The neutral composition disturbance of the $[\mathrm{O}] /\left[\mathrm{N}_{2}\right]$ ratio is located in the same region as the $\left[\mathrm{N}_{2}\right]$ disturbances and nowhere is the value of storm to quiet ratio of $[\mathrm{O}] /\left[\mathrm{N}_{2}\right]$ above 1.0 , both in the MSISE90 empirical model and in our 
theoretical model calculations. Their relative amplitudes, however, differ quite significantly within the subauroral disturbance regions (Fig. 4).

The heating at auroral and subauroral latitudes causes an upwelling. This upward flow tends to decrease the ratio of light gas to heavy gas concentrations, in particular the $[\mathrm{O}] /\left[\mathrm{N}_{2}\right]$ ratio (Rishbeth et al., 1987; Rishbeth, 1998). As the vertical winds are closely related to the divergence and convergence of the horizontal wind system, the large-scale disturbance wind circulation (Fig. 7) suggests that the high to middle latitude upwelling should be completed by downwelling at low to middle latitudes.

The lack of significant deviations of the $R\left(\mathrm{O} / \mathrm{N}_{2}\right)$ parameter from unity at low to middle latitudes points to some additional physical process there which prevents the change of the composition ratio by neutral gas downwelling within a broad altitudinal range $(\approx 200$ $400 \mathrm{~km}$ ). Prölss (1982) has already suggested the possible nonthermal increase of the lighter constituents atomic oxygen and helium relative to the heavier constituents argon and molecular nitrogen, i.e. some nonthermal contributions to composition changes (or their prevention).

To investigate this effect more closely we analyzed the deviation of [O] from the diffusive equilibrium for two different magnetic local time cuts along the geomagnetic meridians versus altitude. Figure 3 in Förster et al. (1999) shows the simulation output regarding the nonthermal effect for the end of the main storm phase (24 UT on January 25). The nonthermal effect for the light thermospheric constituent [O] is clearly height dependent with largest deviations at the lower boundary. During storm time the height range of the nonequilibrium distribution of atomic oxygen expands by about $50 \mathrm{~km}$ toward higher altitudes. The effect is stronger and more extended towards lower latitudes at the Southern (summer) Hemisphere than at the winter hemisphere. The nonthermal deviations of the [O] density near the turbopause (about $100-140 \mathrm{~km}$ altitude) has consequences for the height profile above.

According to Rishbeth and Müller-Wodarg (1999), the vertical distributions of $\mathrm{O}$ and $\mathrm{N}_{2}$ may depart appreciably from diffusive equilibrium at heights up to about $160 \mathrm{~km}$, especially in the summer hemisphere where there is strong upwelling. Förster et al. (1999) showed quantitative estimations of the deviation of [O] from the diffusive equilibrium for different MLT and latitudes both during quiet and disturbed conditions as deduced from the modelling study of the present storm interval. They showed that the deviations begin below about $200 \mathrm{~km}$ and increase with decreasing height and have a level of $10 \%-15 \%$ at about $150 \mathrm{~km}$ altitude. During disturbed conditions the deviations are larger, especially in the summer hemisphere.

Mikhailov et al. (1997) estimated the relative importance of non-barometric effects with respect to purely thermal storm effects for low solar activity conditions using ESRO-4 observations. They showed that the nonthermal deviations are storm-time dependent and depend as well from the actual prehistory of the storm.
According to their estimates, these effects can reach about $35 \%$ of the thermal expansion at 250 to $350 \mathrm{~km}$ altitude (Mikhailov et al., 1997).

\subsection{Positive ionospheric storm}

The positive phase of the ionospheric storm dominates on the dayside during the first day of the storm development and is more intense in the winter hemisphere (Fig. 5 and bottom panel of Fig. 8). Its time evolution correlates well with the meridional thermospheric wind disturbances.

Comparison with data from a global network of ionosonde stations (hourly $N_{m} F_{2}$ measurements of about 50 observatories, not shown here) confirmed in general the model calculations. They show an extended positive storm phase mainly in the Northern (winter) Hemisphere during the second half of the first storm day January 25. For illustration and in comparison with Fig. 10c, d, we included in Table 1 the measured $N_{m} F_{2}$ ratio of disturbed to quiet data (monthly median values served as quiet time reference) measured with ionosondes along the meridians and near the local time of the AE-C overflights. The comparison with the upper two panels of Fig. 10a, b shows that at both local times the "classical" negative phases are generally correlated with the $R(\mathrm{O} /$ $\mathrm{N}_{2}$ ) parameter as expected. Outside the disturbance zones toward middle and low latitudes the electron density indicates positive storm phases. Comparing the upper and the lower panels, compositional changes are obviously not responsible for these positive phases.

A similar investigation of the ionospheric $F_{2}$-layer response to geomagnetic activity using a global network of ionosonde data was performed recently by Field and Rishbeth (1997). They interpret the results of their statistical study for middle and low latitudes in terms of the "composition change theory" of the $F_{2}$-layer storms in a similar way as we have here (Field et al., 1998). They conclude "that changes in thermospheric composition appear to explain adequately changes in the $F_{2}$ layer electron density under disturbed conditions between $50^{\circ} \mathrm{S}$ and $50^{\circ} \mathrm{N}$ magnetic latitude" based on composition variations at a fixed pressure level (not at fixed height as in our study). This is inconsistent with our results. But they notice that "in the winter hemisphere the ionospheric points are mostly well above the MSIS-90 (compositional) curves, usually by $0.1-0.2$ on the logarithmic scale. The dismatch in winter may be due to inaccuracies in MSIS-90, or to the use of wrong inputs to represent quiet and disturbed conditions in the MSIS-90 model, or because composition changes alone are not responsible for the winter effect" (Field and Rishbeth, 1997). We believe that the last assumption is correct. However, we can add that at low latitudes the $F_{2}$ maximum does not follow the constant pressure level movements because of the small inclination of the geomagnetic field lines which allows vertical plasma movements mainly (if not only) due to electromagnetic drift. That is why we prefer to use the fixed height for comparisons of thermospheric and ionospheric varia- 
tions. Nevertheless, our results for fixed pressure level (lower panels at Fig. 10) also reveal no direct correlation between $R$ and $N_{m} F_{2}$ disturbances whereas the latter correlates with meridional wind disturbances.

Thus we can conclude that the positive phase of the ionospheric storm is created by thermospheric winds which cause an upwelling of the ionospheric $F_{2}$-region plasma at middle latitudes along the geomagnetic field lines to heights where the ion loss rate is lower. At low latitudes this enhanced plasma is moved equatorwards by the oppositely directed thermospheric winds blowing from the northern and southern high latitudes.

We have calculated self-consistently the electric fields both of magnetospheric and dynamo origin in our modelling study. As Fig. 9 shows, the shielding of the magnetospheric electric field is highly effective and prevents the penetration of large electric field disturbances toward mid and low latitudes. But there are indications of quasi simultaneous changes of the disturbance zonal electric field component (e.g. near 0300 UT and 1200 UT). They coincide with rapid increases of the $\mathrm{AE}$ index or the cross-polar potential drop respectively (see Fig. 1) and are of short duration $(\sim 1 \mathrm{~h})$. This could be due to some weak penetration effects resulting from magnetospheric electric field changes. In general, however, continuous disturbance electric fields are present during the storm day which are probably due to the disturbance dynamo. They help to create positive ionospheric disturbances during daytime at mid to low latitudes. But their contribution is much less (except, possibly, at the magnetic equator) in comparison with the meridional wind disturbance amplitudes.

The positive effect is partially caused by the absolute density enhancement of all neutral constituents. For daylight conditions enhanced [O] density favours ion production; loss processes are also enhanced, but to a lesser extent. According to Mikhailov et al. (1995) (Appendix B) this is first true for the longitudinal sector where the storm onset took first place at local night-time hours, hence in the American sector for our case study (Fig. 10b, d).

The negative $F$-region electron density disturbance does not always directly correlate with the neutral composition behavior. The best correlation is at subauroral and adjacent mid latitudes, but apparently competing effects exist (compare Figs. 4 and 5 as well as the two lower panels in Fig. 8). The most likely candidates are precipitation and electromagnetic ion drift effects (ion transport and heating) at the winter high latitudes. In the Southern (summer) Hemisphere, the negative phase has already begun during the first storm day to propagate equatorward to middle and low latitudes.

\section{Conclusions}

Our modelling case study shows that the global numerical Upper Atmosphere Model (UAM) describes the modelled situation of a moderate magnetic storm during northern winter solstice under low solar activity quite satisfactorily both for thermospheric and ionospheric parameter disturbances. We conclude that the main cause for the positive ionospheric storm phase is an upwelling and equatorward moving of the ionospheric $F_{2}$-region plasma by thermospheric winds with additional (but not important) contributions from some other processes. The meridional neutral wind component moves the plasma at mid latitudes along the geomagnetic field lines to the heights where the ion loss rate is lower. At low latitudes this enhanced plasma is moved equatorwards by the oppositely directed thermospheric winds blowing from the northern and southern high latitudes. Electromagnetic drifts due to penetrating magnetospheric electric fields and dynamo action could also play a role. It appears that neutral compositon changes in the mid- to low-latitude thermosphere as recently suggested by TGCM studies (e.g., Burns et al., 1995a) do not play a significant role for positive ionospheric storms although some contributions arise from the general thermal expansion and nonthermal distribution effects.

The negative phase is a combination of the effects of the neutral composition changes dominating at subauroral and adjacent mid latitudes and those of precipitation, ion transport and heating due to electric fields at high latitudes.

Acknowledgements. This work was supported by the Grant 98-0564145 of the Russian Foundation for Basic Research. The ionosonde data were provided from the World Data Centre C1 for Solar-Terrestrial Physics; the delivery of ionosonde data from the two stations Johannesburg and Hermanus by Lee-Anne McKinnell is gratefully acknowledged. In addition, the authors would like to thank Richard Holme for his assistance with English style and grammar.

Topical Editor M. Lester thanks G. Millward and H. Rishbeth for their help in evaluating this paper.

\section{References}

Burns, A. G., and T. J. Killeen, The equatorial neutral thermosphere response to geomagnetic forcing, Geophys. Res. Lett., 19, 977-980, 1992.

Burns, A. G., T. J. Killeen, G. R. Carignan, and R. G. Roble, Large enhancements in the $\mathrm{O} / \mathrm{N}_{2}$ ratio in the evening sector of the winter hemisphere during geomagnetic storms, J. Geophys. Res., 100, 14661-14671, 1995a.

Burns, A. G., T. J. Killeen, W. Deng, G. R. Carignan, and R. G. Roble, Geomagnetic storm effects in the low- to middle-latitude upper thermosphere, J. Geophys. Res., 100, 14 673-14 691, 1995 b.

Burnside, R. G., C. A. Tepley, M. P. Sulzer, T. F. Fuller-Rowell, D. G. Torr, and R. G. Roble, The neutral thermosphere at Arecibo during geomagnetic storms, J. Geophys. Res., 96, 1289 1301, 1991.

Burrage, M. D., V. J. Abreu, N. Orsini, C. G. Fesen, and R. G. Roble, Geomagnetic activity effects on the equatorial neutral thermosphere, J. Geophys. Res., 97, 4177-4187, 1992.

Crowley, G., B. A. Emery, R. G. Roble, H. C. Carlson Jr., and D. J. Knipp, Thermospheric dynamics during September 18-19, 1984, 1. Model simulations, J. Geophys. Res., 94, 16 925-16 944, 1989.

Danilov, A. D., and L. D. Morozova, Ionospheric storms in the $F_{2}$-region. Morphology and physics (review), Geomagn. Aeron. (Engl. translation), 25, 593-605, 1985.

Dickinson, R. E., E. C. Ridley, and R. G. Roble, A threedimensional general circulation model of the thermosphere, J. Geophys. Res., 86, 1499-1512, 1981. 
Dickinson, R. E., E. C. Ridley, and R. G. Roble, Thermospheric general circulation with coupled dynamics and composition, J. Atmos. Sci., 41, 205-219, 1984.

Fejer, B. G., and L. Scherliess, Time dependent response of equatorial ionospheric electric fields to magnetospheric disturbances, Geophys. Res. Lett., 22, 851-854, 1995.

Field, P. R., and H. Rishbeth, The response of the ionospheric F2-layer to geomagnetic activity: an analysis of worldwide data, J. Atmos. Solar-Terr. Phys., 59, 163-180, 1997.

Field, P. R., H. Rishbeth, R. J. Moffett, D. W. Idenden, G. H. Millward, and A. D. Aylward, Modelling composition changes in F-layer storms, J. Atmos. Solar-Terr. Phys., 60, 523-543, 1998.

Förster, M., A. A. Namgaladze, and R. Y. Yurik, Thermospheric composition changes deduced from geomagnetic storm modelling, Geophys. Res. Lett., 26, 2625-2628, 1999.

Fuller-Rowell, T. J., and D. Rees, A three-dimensional timedependent global model of the thermosphere, J. Atmos. Sci., 37, 2545-2567, 1980

Fuller-Rowell, T. J., and D. Rees, Derivation of a conservation equation for a mean molecular weight for a two-constituent gas within a three-dimensional, time-dependent model of the thermosphere, Planet. Space Sci., 31, 1209-1222, 1983.

Fuller-Rowell, T. J., D. Rees, S. Quegan, R. J. Moffett, and G. J. Bailey, Interactions between neutral thermospheric composition and the polar ionosphere using a coupled ionosphere-thermosphere model, J. Geophys. Res., 92, 7744-7748, 1987.

Fuller-Rowell, T. J., D. Rees, S. Quegan, R. J. Moffett, and G. J. Bailey, Simulation of the seasonal and universal time variations of the high-latitude thermosphere and ionosphere using a coupled three-dimensional model, Pure Appl. Geophys., 127, 189-218, 1988.

Fuller-Rowell, T. J., D. Rees, B. A. Tinsley, H. Rishbeth, A. S. Rodger, and S. Quegan, Modelling the response of the thermosphere and ionosphere to geomagnetic storms: effects of a midlatitude heat source, Adv. Space Res., 10, 215-223, 1990.

Fuller-Rowell, T. J., D. Rees, H. Rishbeth, A. G. Burns, T. L. Killeen, and R. G. Roble, The composition change theory of F-region storms: a reassessment, J. Atmos. Terr. Phys., 53, 797-815, 1991.

Fuller-Rowell, T. J., M. V. Codrescu, R. J. Moffett, and S. Quegan, Response of the thermosphere and ionosphere to geomagnetic storms, J. Geophys. Res., 99, 3893-3914, 1994.

Fuller-Rowell, T. J., D. Rees, S. Quegan, R. J. Moffett, M. V. Codrescu, and G. H. Millward, A coupled thermosphereionosphere model (CTIM), in STEP handbook on ionospheric models, Ed. R. W. Schunk, 217-238, Utah State University, USA, 1996.

Hall, C. M., A. Brekke, O. V. Martynenko, and A. A. Namgaladze, Modelling turbulent energy dissipation in the high-latitude mesosphere, J. Atmos. Solar-Terr. Phys., 60, 331-336, 1998.

Hardy, D. A., M. S. Gussenhoven, and E. A. Holeman, A statistical model of auroral electron precipitation, J. Geophys. Res., 90, 4229-4248, 1985.

Hedin, A. E., P. Bauer, H. G. Mayr, G. R. Carignan, L. H. Brace, H. C. Brinton, A. D. Parks, and D. T. Pelz, Observations of neutral composition and related ionospheric variations during a magnetic storm in February 1974, J. Geophys. Res., 82, 3183$3189,1977$.

Jones, K. L., and H. Rishbeth, The origin of storm increases of midlatitude F-layer electron concentration, J. Atmos. Terr. Phys., 33, 391-401, 1971.

Korenkov, Y., F. Bessarab, V. Klimenko, V. Surotkin, and V. Smertin, Numerical modelling of the thermosphere-ionosphere coupling during substorm, Adv. Space Res., 18, 41-44, 1996a.

Korenkov, Y. N., V. V. Klimenko, M. Förster, V. A. Surotkin, and J. Smilauer, Global modelling study (GSM TIP) of the ionospheric effects of excited $\mathrm{N}_{2}$, convection and heat fluxes by comparison with EISCAT and satellite data for 31 July 1990, Ann. Geophysicae, 14, 1362-1374, 1996 b.
Leontyev, S. V., A. A. Namgaladze, A. N. Namgaladze, and N. N. Bogdanov, Thermospheric meridional winds in the vicinity of the auroral zone: observations and modelling, J. Atmos. Solar-Terr. Phys., 60, 215-226, 1998.

Matuura, N., Theoretical models of ionospheric storms, Space Sci. Rev., 13, 129-189, 1972.

Mikhailov, A. V., M. G. Skoblin, and M. Förster, Day-time $F$-layer positive storm effect at middle and lower latitudes, Ann. Geophysicae, 13, 532-540, 1995.

Mikhailov, A. V., M. Förster, and M. G. Skoblin, An estimate of the non-barometric effect in [O] height distribution at low latitudes during magnetically disturbed periods, J. Atmos. Solar-Terr. Phys., 59, 1209-1215, 1997.

Millward, G. H., R. J. Moffett, S. Quegan, and T. J. Fuller-Rowell, A coupled thermosphere-ionosphere-plasmasphere model (CTIP), in STEP handbook on ionospheric models, Ed. R. W. Schunk, 239-280, Utah State University, USA 1996.

Namgaladze, A. A., Y. N. Korenkov, V. V. Klimenko, I. V. Karpov, F. S. Bessarab, V. A. Surotkin, T. A. Glushchenko, and N. M. Naumova, Global model of the thermosphere-ionosphere-protonosphere system, Pure Appl. Geophys., 127, 219254, 1988.

Namgaladze, A. A., Y. N. Korenkov, V. V. Klimenko, I. V. Karpov, V. A. Surotkin, and N. M. Naumova, Numerical modelling of the thermosphere-ionosphere-protonosphere system, J. Atmos. Terr. Phys., 53, 1113-1124, 1991.

Namgaladze, A. A., O. V. Martynenko, A. N. Namgaladze, M. A. Volkov, Y. N. Korenkov, V. V. Klimenko, I. V. Karpov, and F. S. Bessarab, Numerical simulation of an ionospheric disturbance over EISCAT using a global ionospheric model, J. Atmos. Terr. Phys., 58, 297-306, 1996.

Namgaladze, A. A., O. V. Martynenko, and A. N. Namgaladze, Global model of the upper atmosphere with variable latitudinal integration step, Geomagn. Aeron. Int., 1, 53-58, 1998a.

Namgaladze, A. A., O. V. Martynenko, M. A. Volkov, A. N. Namgaladze, and R. Y. Yurik, High-latitude version of the global numerical model of the Earth's upper atmosphere, Proc. Murmansk State Technical University, 1, 23-84, 1998b.

Namgaladze, A. A., A. N. Namgaladze, and M. A. Volkov, Seasonal effects in the ionosphere-thermosphere response to the precipitation and field-aligned current variations in the cusp region, Ann. Geophysical, 16, 1283-1298, 1998c.

Peymirat, C., A. D. Richmond, B. A. Emery, and R. G. Roble, A magnetosphere thermosphere ionosphere electrodynamics general circulation model, J. Geophys. Res., 103, 17467-17477, 1998.

Prölss, G. W., Magnetic storm associated perturbations of the upper atmosphere: recent results obtained by satellite-borne gas analyzers, Rev. Geophys. Space Phys., 18, 183-202, 1980.

Prölss, G. W., Latitudinal structure and extension of the polar atmospheric disturbance, J. Geophys. Res., 86, 2385-2396, 1981.

Prölss, G. W., Perturbation of the low-latitude upper atmosphere during magnetic substorm activity, J. Geophys. Res., 87, 52605266, 1982.

Prölss, G. W., On explaining the local time variation of ionospheric storm effects, Ann. Geophysicae, 11, 1-9, 1993.

Prölss, G. W., Ionospheric F-region storms, in Handbook of atmospheric electrodynamics, Ed. H. Volland, vol 2, 195-248, CRC Press, Boca Raton, 1995.

Prölss, G. W., Magnetic storm associated perturbations of the upper atmosphere, in Magnetic storms, Eds. T. Tsurutani, W. D. Gonzalez, Y. Kamide, and J. K. Arballo, vol 98 of Geophysical Monograph, 227-241, American Geophysical Union, 1997.

Prölss, G. W., S. Werner, M. V. Codrescu, T. J. Fuller-Rowell, A. G. Burns, and T. L. Killeen, The thermospheric-ionospheric storm of December 8, 1982: model predictions and observations, Adv. Space Res., 22, 123-128, 1998.

Richmond, A. D., E. C. Ridley, and R. G. Roble, A thermosphere/ ionosphere general circulation model with coupled electrodynamics, Geophys. Res. Lett., 19, 601-604, 1992. 
Rishbeth, H., How the thermospheric circulation affects the ionospheric $F_{2}$-layer, J. Atmos. Solar-Terr. Phys., 60, 13851402, 1998.

Rishbeth, H., and I. C. F. Müller-Wodarg, Vertical circulation and thermospheric composition: a modelling study, Ann. Geophysicae, 17, 794-805, 1999.

Rishbeth, H., T. J. Fuller-Rowell, and D. Rees, Diffusive equilibrium and vertical motion in the thermosphere during a severe magnetic storm: a computational study, Planet. Space Sic., 35, 1157-1165, 1987.

Roble, R. G., E. C. Ridley, A. D. Richmond, and R. E. Dickinson, A coupled thermosphere/ionosphere general circulation model, Geophys. Res. Lett., 15, 1325-1328, 1998.

Skoblin, M. G., and M. Förster, Steep latitudinal gradients of thermospheric composition during magnetic storms: a possible formation mechanism, Ann. Geophysicae, 13, 277-284, 1995.
Skoblin, M. G., and A. V. Mikhailov, Some pecularities of altitudinal distribution of atomic oxygen at low latitudes during magnetic storms, J. Atmos. Terr. Phys., 58, 875-881, 1996.

Volkov, M. A., and A. A. Namgaladze, Models of field-aligned currents needful to simulate the substorm variations of the electric field and other parameters observed by EISCAT, Ann. Geophysicae, 14, 1356-1361, 1996.

Wei, D., and M. Förster, Changes of thermospheric composition and the response of the ionosphere during the magnetic storm of January, 1974, Gerlands Beitr. Geophysik, 98, 240-250, 1989.

Weimer, D. R., N. C. Maynard, W. J. Burke, and C. Liebrecht, Polar cap potentials and the auroral electrojet indices, Planet. Space Sci., 38, 1207-1222, 1990.

Zuzic, M., L. Scherliess, and G. W. Prölss, Latitudinal structure of thermospheric composition perturbations, J. Atmos. Solar-Terr. Phys., 59, 711-724, 1997. 